\title{
Recovering from Research: A No-Fault Proposal to Compensate Injured Research Participants
}

\author{
Elizabeth R. Pike ${ }^{\dagger}$
}

\section{CONTENTS}

I. INTRODUCTION

II. Why RESEARCH PARTICIPANTS SHOULD BE COMPENSATED FOR INJURIES

A. The Biomedical Research Enterprise.............................................11

B. Historical Abuses and Current Research Participant Protections

C. National Advisory Committees Consider Compensating Injured Research Participants

III. CONTINUED RELIANCE ON THE TORT SYSTEM TO COMPENSATE

INJURED RESEARCH PARTICIPANTS IS MORALLY INDEFENSIBLE

A. Injured U.S. Participants Receive No Systematic Compensation

B. The Tort System Poses Serious Challenges for All

Research Participants...

C. Several Classes of Research Participants Are

Systematically Uncompensated....

1. U.S. Participants in Federally Conducted Research ......................30

2. International Participants in Federally

Conducted Research

3. International Participants in Privately

Conducted Research

a. Substantive Barriers to Recovery: Corporate Liability

Under the Alien Tort Statute

+ Post-Doctoral Fellow, Department of Bioethics, National Institutes of Health; Research Staff Member, Presidential Commission for the Study of Bioethical Issues. I am extremely thankful to have had such thoughtful review of this Article by Seema Shah, Ben Berkman, Andy Pike, Barbara Sarshik, Karen Rothenberg, and Lindsay Wiley. I am eternally grateful to David Vanca for his invaluable insights. This research was supported by the Intramural Research Program of the National Institutes of Health, out of the Warren G. Magnussen Clinical Center. The opinions expressed here are my own. They do not represent any position or policy of the U.S. National Institutes of Health, the Public Health Service, the Presidential Commission for the Study of Bioethical Issues, or the Department of Health and Human Services. 
b. Procedural Obstacle to Recovery: Forum

Non Conveniens

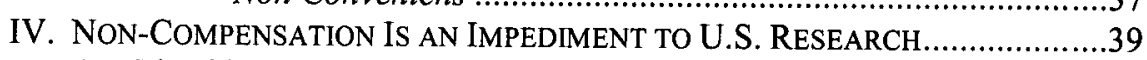

A. The Globalization of Biomedical Research ........................................39

B. Consensus to Compensate Among Countries

Involved in Research..

C. Lack of Systematic Compensation Delays Important

U.S.-Sponsored Biomedical Research

V. THE UNITED STATES SHOULD IMPLEMENT NO-FAULT COMPENSATION

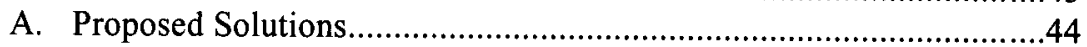

1. Modified Disclosure ..............................................................44

2. Mandated No-Fault Compensation System.................................45

B. No-Fault Compensation Systems ..............................................47

1. Insurance/Self-Insurance Requirement .......................................48

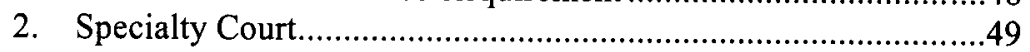

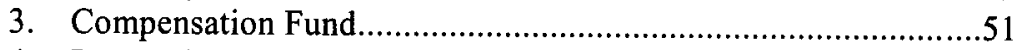

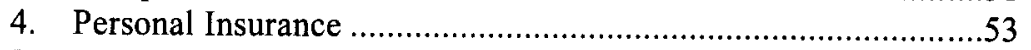

C. Proposed Parameters .................................................................53

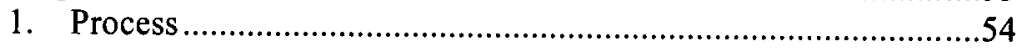

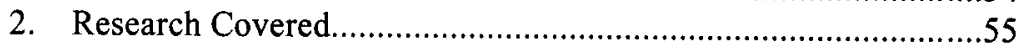

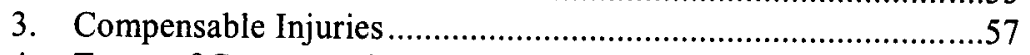

4. Types of Compensation ........................................................5

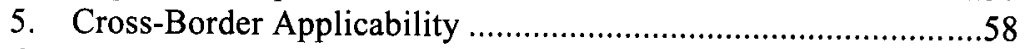

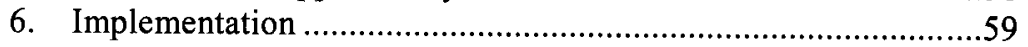

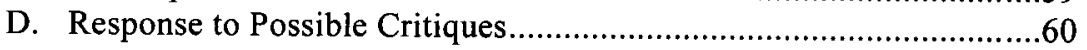

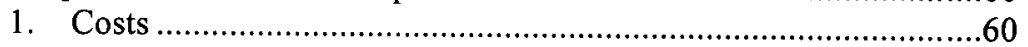

2. Not Actually a Problem? ..................................................61

3. Now Is Not the Time ........................................................61

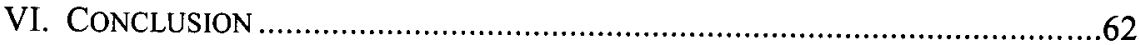

National advisory committees have considered the obligations owed to research participants in the event of research-related injuries. These committees have repeatedly concluded that injured research participants are entitled to compensation for their injuries, that the tort system provides inadequate remedies, and that the United States should adopt no-fault compensation. But because the advisory committees have made no concrete proposals and have taken no steps toward implementing no-fault compensation, the United States continues to rely on the tort system to compensate injured research participants.

This Article argues that recent legal developments and a transformation in the global research landscape make maintaining the status quo morally indefensible and practically unsustainable. Recent legal developments exacerbate the longstanding difficulties associated with the tort system as a method of compensation; nearly every injured research participant will have difficulty recovering damages, and certain classes of injured research participants-those in federal research and those abroad-are prevented from recovering altogether, resulting in substantial unfairness. In the past ten years, many of the countries substantially involved in research have mandated systematic compensation. By not mandating compensation, the United States has become a moral outlier and risks having its noncompliant 
research embargoed by foreign ethics committees, thereby delaying important biomedical advances.

This Article examines alternative compensation mechanisms and offers a concrete no-fault compensation proposal built on systems already in place. The proposed system can be implemented in the United States and countries around the world to help harmonize various national compensation systems and to more equitably and effectively make those injured by research whole.

\section{INTRODUCTION}

In the spring of 1993, Participant 10, an asymptomatic carrier of Hepatitis B, enrolled in a National Institutes of Health $(\mathrm{NIH})$ clinical trial of an experimental drug Fialuridine (FIAU), a potential wonder drug for the treatment of Hepatitis B. ${ }^{1}$ Three months into the trial, however, researchers suspected something had gone terribly wrong. The first research participant was rushed to the hospital with organ failure. By July 30 , five of the ten research participants had died from an unforeseen FIAU toxicity. ${ }^{2}$ Patient 10 was among the luckier of the research participants; he was rushed to the hospital, received a liver transplant, and survived-albeit after falling into a coma, spending four months in the hospital, and looking at a lifetime of medication to prevent his body from rejecting the transplant. ${ }^{3}$

The FIAU experiment raised serious concerns within the research community, and commissions were convened to evaluate the trial. A Food and Drug Administration (FDA) committee reached conclusions that were critical of the NIH researchers, ${ }^{4}$ but independent panels of the NIH and the Institute of Medicine-an agency within the National Academy of Sciences-cleared the researchers of any wrong-doing, finding that there was "no evidence of negligence or carelessness on the part of the investigators or sponsors." 5

The FIAU research was not the only biomedical research trial that made headlines, resulted in lawsuits, and prompted increased scrutiny of research. In 1996, Pfizer conducted research on Trovan, a potential blockbuster drug, during an outbreak of bacterial meningitis in Kano, Nigeria. A Washington Post exposé published allegations of research abuses during the Trovan trial that formed the basis of the novel The Constant Gardener ${ }^{7}$ and a headline-making lawsuit. ${ }^{8}$ In 1999, Jesse Gelsinger - an eighteen-year-old enrolled in a gene transfer experiment-died unexpectedly because of the research intervention, resulting in a lawsuit and an undisclosed settlement. ${ }^{9}$ In 2010 , Professor Susan Reverby uncovered evidence that

${ }^{1}$ See, e.g., Susan Levine, Clinical Trial Was Near-Death Experience Worth His While, L.A. Times, Aug. 13, 2001, at S5.

${ }^{2} I d$.

${ }^{3}$ One other research participant also survived after receiving an organ transplant. $I d$.

${ }^{4}$ See, e.g., Edwin Chen, FDA Faults Drug Testers in Patient-Death Probe, L.A. TimES, May 14, 1994, at A16.

${ }^{5}$ INST. OF MED., REVIEW OF THE FIALURIdiNe (FIAU) CliniCAL TRIALS 12, 152 (1995).

${ }^{6}$ See Joe Stephens, Where Profits and Lives Hang in Balance, WASH. POST, Dec. 17, 2000, at A1.

${ }^{7}$ See, e.g., Jim Edwards, Claim: LeCarre's "The Constant Gardener" Was Based on Pfizer Trovan Case, CBS News (Feb. 17, 2009, 9:39 PM), http:/www.bnet.com/blog/drug-business/claimlecarre-8217s-8220the-constant-gardener-8221-was-based-on-pfizer-trovan-case $/ 653$.

${ }^{8}$ See Abdullahi v. Pfizer, 562 F.3d 163 (2d Cir. 2009), cert. denied, 130 S. Ct. 3541 (2010). The case is discussed in more detail in Part III.C. 3.

${ }^{9}$ See, e.g., Ezekiel J. Emanuel et al., Ethical and Regulatory Aspects of Clinical RESEARCH: READINGS AND COMMENTARY 369 (2003). 
between 1946 and 1948, U.S. researchers deliberately infected prisoners and mental health patients in Guatemala with gonorrhea and syphilis to test the untreated progression of the diseases. ${ }^{10}$ On March 16, 2011, a class-action lawsuit stemming from this research was filed in U.S. court. ${ }^{11}$

These and other cases of research injuries raised important questions about the obligations owed to injured research participants and whether the legal system is the appropriate mechanism to fulfill these obligations. These important questions have not been adequately addressed. A series of national advisory committees convened to consider the obligations owed in the event of research-related injury have concluded repeatedly that injured research participants are entitled to compensation for their injuries, that the tort system provides inadequate remedy, and that the United States should consider some form of no-fault compensation. ${ }^{12}$ But because the advisory committees have made no concrete proposals and have taken no steps to implement no-fault compensation, the United States continues to rely on the tort system to compensate injured research participants.

This Article is the first to analyze the developments in the legal landscape and the global research landscape that render continued reliance on the tort system morally indefensible and a significant impediment to U.S. research conducted abroad. Part II provides background on the unique aspects of biomedical research that warrant additional protections for research participants, including no-fault compensation for injuries. Part III argues that continued reliance by the United States on the tort system to compensate injured research participants is morally indefensible in light of recent legal developments. The tort system poses challenges unique to research participants that are difficult to overcome and insurmountable for certain classes of research participants, resulting in substantial unfairness.

Part IV argues that the U.S. policy of not compensating injured research participants is an impediment to U.S. research conducted abroad. In the past decade, the research enterprise has become increasingly global, and nearly every country that sponsors, hosts, or conducts substantial amounts of research has required that injured research participants receive systematic compensation. ${ }^{13}$ The United States not only is a moral outlier, but also risks having its research embargoed abroad, thereby delaying potential medical advances. Part $\mathrm{V}$ argues that the United States should implement no-fault compensation for research-related injuries. After examining a number of solutions, this Article concludes with a proposal that satisfies the moral obligation owed to injured research participants, more equitably and effectively compensates those injured by research at low cost, and can be implemented globally to harmonize various national compensation systems.

\section{WHY RESEARCH PARTICIPANTS SHOULD BE COMPENSATED FOR INJURIES}

Biomedical research has led to some of the most important medical advances of the past century. Extremely serious and widespread diseases that plagued prior generations-yellow fever, polio, measles, diphtheria, and pertussis-have been

10 See, e.g., Susan M. Reverby, "Normal Exposure" and Inoculation Syphilis: A PHS

"Tuskegee" Doctor in Guatemala, 1946-1948, 23 J. POL'Y HIST. 6 (2011).

${ }^{11}$ Class Action Complaint for Injunctive Relief and Damages, Garcia v. Sebelius, No. 1:11-cv00527-RBW (D.D.C. Mar. 14, 2011).

${ }^{12}$ See infra Part II.C.

${ }^{13}$ See Seth W. Glickman et al., Ethical and Scientific Implications of the Globalization of Clinical Research, 360 NEW ENG. J. MED. 816, 816-17 (2009). 
almost eradicated through vaccines developed using complex and ground-breaking research. ${ }^{14}$ Biomedical research has also given rise to insulin treatment for diabetes, antibiotics for treating a wide variety of diseases, medication for high blood pressure, new surgical techniques, increasingly successful treatments for cancer, and improved treatments for AIDS. ${ }^{15}$ As scholars have noted, "the extensive benefits that we have come to expect from medical care undoubtedly depend upon the discoveries of medical research."16

But unlike medical care, which treats individual patients, biomedical research creates generalizable knowledge to benefit future patients. Research participants themselves are often only incidental beneficiaries. ${ }^{17}$ Because research requires that individuals assume additional risk for the benefit of others, unethical researchers have historically used participants as means to an end without regard for their safety or well-being.

As a result of past research abuses, research today is heavily regulated with increased participant protections. Though generally well-protected throughout the research process, research participants are critically unprotected under U.S. law and international ethical guidelines once research injuries occur. For four decades, U.S. advisory committees have considered and reconsidered whether there is an obligation to compensate research participants who become injured as a result of participating in research. ${ }^{18}$ Despite repeated recognition of such an obligation, U.S. advisory committees have made no concrete proposals and have taken no steps to implement systematic compensation. ${ }^{19}$

\section{A. The Biomedical Research ENTERPRise}

Biomedical research is the study of diseases and conditions and the various methods, drugs, and devices used to treat them. ${ }^{20}$ Biomedical research shares some superficial similarities with medical care: both biomedical research and medical care aim to improve health through medical interventions, and both biomedical research and medical care are conducted by doctors in medical facilities. ${ }^{21}$

But research, at its core, is fundamentally different from medical care. Medical care is dedicated to providing individual patients with the best treatments for their particular disease. ${ }^{22}$ Biomedical research, by contrast, has one primary goal: the

14 See, e.g., Ctrs. for Disease Control \& Prevention, Impact of Vaccines Universally Recommended for Children-United States, 1990-1998, 48 MORBIDITY \& MORTALITY WKLY. REP. 243, 243-48 (1999).

${ }^{15}$ See EMANUEL ET AL., supra note 9, at xv.

${ }^{16}$ See, e.g., Paul Litton \& Franklin G. Miller, A Normative Justification for Distinguishing the Ethics of Clinical Research from the Ethics of Medical Care, 33 J.L. MED. \& ETHics 566, 568 (2005).

${ }^{17}$ See, e.g., E. Haavi Morreim, Litigation in Clinical Research: Malpractice Doctrines Versus Research Realities, 32 J.L. MED. \& ETHICS 474, 475 (2004) ("[I]t is not the goal of any research protocol to benefit any specified individual. That happens by good fortune, not by design.").

${ }^{18}$ See infra Part II.C.

${ }^{19}$ See infra Part II.C.

${ }^{20}$ See Steven Joffe \& Franklin Miller, Bench to Bedside: Mapping the Moral Terrain of Clinical Research, 38 HASTINGS CENTER REP. 30, 32 (2008).

${ }^{21}$ Franklin G. Miller, Revisiting the Belmont Report: The Ethical Significance of the Distinction Between Clinical Research and Medical Care, APA NEwSLS.: NEWSL. ON PHIL. \& MED., Spring 2006, at $10-11$.

${ }^{22}$ See, e.g., Morreim, supra note 17, at 475. 
creation of generalizable knowledge that can be used to benefit future patients. ${ }^{23}$ Research is not conducted primarily to provide the best medical treatment for individual research participants. ${ }^{24}$ In fact, many elements of research-placebocontrolled trials, random assignment to treatment arms, restricted flexibility in adjusting dosages, restrictions on using concomitant medications-are contrary to good medical care. ${ }^{25}$ Research participants may also undergo a number of procedures to measure study outcomes - including blood draws, biopsies, radiologic scans, and lumbar punctures - that carry burdens or risk without any compensating medical benefit. ${ }^{26}$

The different aims of medical care and biomedical research give rise to different relationships. The doctor-patient relationship is a fiduciary relationship, and patients are entitled to rely on doctors' learned judgments. ${ }^{27}$ Doctors, in return, owe patients a duty of care to act in the patients' best interests. ${ }^{28}$ As is true of most fiduciary relationships, dependency and trust permeate the doctor-patient relationship. ${ }^{29}$ As discussed in more detail in Part II.B, the same is not entirely true of the researcherparticipant relationship. The law requires researchers to disclose potential harms of the research, but researchers need not advise potential participants as to whether participation is in their best interests. ${ }^{30}$ While trust and dependency may develop in the researcher-participant relationship, these attributes are not the cornerstone of the researcher-participant relationship. ${ }^{31}$

The very nature of research requires that participants assume some risk of harm for the benefit of others, ${ }^{32}$ giving rise to a risk-benefit profile that is often different from that of medical care. In providing medical care, a doctor is expected to weigh the risks and benefits of a particular intervention and prescribe a course of action only if the benefits outweigh the risks for that particular patient. ${ }^{33}$ The same is not true for research. In accordance with established international ethical guidelines, the risks of research must be favorably balanced by the combined benefit to the individual and to society as a whole. ${ }^{34}$ Some research that is considered routine and ethical poses net risk to individual participants. ${ }^{35}$

${ }^{23}$ Grimes v. Kennedy Krieger Inst., Inc., 782 A.2d 807, 838 (Md. 2001) ("The experiment is driven by the investigator's dedication to the advancement of knowledge . . ; it is also driven by society's interest in future benefits that will flow from medical discoveries.").

${ }^{24}$ See, e.g., Joffe \& Miller, supra note 20, at 40; Morreim, supra note 17, at 475 ("The goal of research is fundamentally different. It does not aim to benefit any specific individual, but rather to advance generalizable knowledge and thereby to benefit broader populations.").

${ }^{25}$ See, e.g., Miller, supra note 21 , at 10,11 .

${ }^{26}$ See, e.g., id. at 11.

${ }^{27}$ See, e.g., E. Haavi Morreim, Medical Research Litigation and Malpractice Tort Doctrines: Courts on a Learning Curve, 4 Hous. J. HEALTH L. \& POL'Y 1, $42-43$ (2003) ("[C]ourts have felt free to call the standard physician-patient relationship fiduciary or at least a relationship of trust and confidence. The physician has knowledge and skills for which the patient has significant need.").

${ }^{28}$ See id. at 64.

${ }^{29} \mathrm{See}$, e.g., $i d$. at $43-44$ ("The result is a relationship bearing the classic loyalty duties fiduciaries owe their beneficiaries.").

${ }^{30}$ See id. at 47.

${ }^{31}$ At times, the doctor and researcher roles are not as dichotomous as set forth above; for instance, a primary care physician can enroll patients as research participants and may help conduct the research.

${ }^{32}$ See, e.g., James Childress, Compensating Injured Research Subjects: I. The Moral Argument, 6 HASTINGS CENTER REP. 21, 22 (1984) (noting that research participants have "taken certain risks for the benefit of society through the advancement of medical knowledge").

${ }_{33}^{3}$ See, e.g., Joffe \& Miller, supra note 20 , at 30.

${ }^{34}$ See, e.g., Criteria for IRB Approval of Research, 45 C.F.R. $\S 690.111$ (a)(2) (2011) ("Risks to subjects are reasonable in relation to anticipated benefits, if any, to subjects, and the importance of the 
Given the potentially unfavorable risk-benefit profile, why do people agree to participate in research? The first, and most simplistic, answer is that potential participants may not understand this fundamental difference between research and care. While there is empirical support for this supposition, ${ }^{36}$ it is not the full answer. A more complete answer is that individuals participate in research for a variety of reasons, some self-interested and some altruistic. Healthy individuals may choose to enroll in disease-specific research to help or honor a loved one who has battled the disease, or out of gratitude for the medical advances that they have enjoyed due to past research participation. ${ }^{37}$ Sick participants may enroll in research to obtain care and treatment otherwise unavailable outside the research context, or to generate knowledge about their disease that benefits future patients. ${ }^{38}$ The uninsured may enroll in research to access care or treatment otherwise unavailable to them. ${ }^{39}$ Individuals in developing countries may enroll in research because "financial compensation for research participation may exceed participants' annual wages, and participation in a clinical trial may provide the only access to care for persons with the condition under study." ${ }^{40}$ Others may choose to participate solely for the payment that they receive for participating. ${ }^{41}$ In some egregious historical cases, participants were enrolled unknowingly and unwittingly. ${ }^{42}$ These reasons contrast greatly with the primary reason patients participate in medical care: to get better.

This fundamental difference between the goals of medical care and the goals of biomedical research-treating individual patients versus creating generalizable knowledge-manifests itself in different types of relationships (doctor-patient versus researcher-participant), different risk-benefit profiles, and different reasons for participating. As discussed in Part III.B, these distinctions are important in

knowledge that may reasonably be expected to result."); COUNCIL FOR INT'L ORGS. OF MED. SCIS. \&

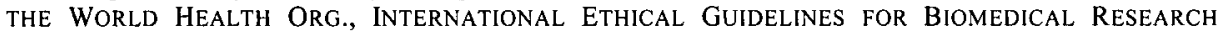
INVOLVING HUMAN SUBJECTS, guideline 8 (2002) [hereinafter CIOMS (2002)] ("Risks of interventions that do not hold out the prospect of direct diagnostic, therapeutic or preventive benefit for the individual must be justified in relation to the expected benefits to society."); WORLD MED. Ass'N, Declaration of Helsinki: Ethical Principles for Medical Research Involving HUMAN SUBJECTS $\S$ B.18 (1964) (noting that risks of research must be compared with "foreseeable benefits to them and to other individuals or communities affected by the condition under investigation").

${ }^{35}$ See, e.g., Grimes v. Kennedy Krieger Inst., Inc., 782 A.2d 807, 838 (Md. 2001) ("[T]he price of a bad outcome is exacted from the individual who suffers the untoward reaction, whereas the benefit of the breakthrough is available to society as a whole.").

${ }^{36}$ See sources cited infra note 110.

${ }^{37}$ See, e.g., Litton \& Miller, supra note 16, at 569.

${ }^{38}$ See, e.g., id.; Ruth Macklin, The Belmont Principles of Justice: An Idea Whose Time Has Come, APA NEWSLS.: Newsl. ON PHIL. \& MED., Spring 2006, at 5. While some research participants fare better simply because of increased medical attention during the trial, see, e.g., Morreim, supra note 17 , at 475 , there is certainly no guarantee that treatment in research will be successful. Of all drugs tested for later FDA approval, approximately eighty percent fail. Even in the later phases of research, randomization can mean that research participants are assigned treatment that is less effective. See, e.g., id.

${ }^{39}$ See, e.g., Christine Pace, Franklin G. Miller \& Marion Danis, Enrolling the Uninsured in Clinical Trials: An Ethical Perspective, 31 CRITICAL CARE MED. S121, S122 (2003).

${ }^{40}$ See, e.g., Glickman et al., supra note 13 , at 818 .

${ }^{41}$ For a discussion of those who make a living by participating in research, and the troubling implications thereof, see Carl Elliott, Guinea-Pigging, THE NEW YORKER, Jan. 7, 2008, at 36. Empirical data suggest that Phase I participants are motivated to participate in research equally by a desire to help as by money. See Pamela R. Ferguson, Clinical Trials and Healthy Volunteers, 16 MED. L. REV. 23, 32-34 (2008).

${ }^{42}$ For examples of non-consensual research, see cases cited infra note 146, and the Guatemala and Tuskegee studies discussed supra in the Introduction. 
determining what obligations are owed to injured research participants and how the legal system should fulfill those obligations. ${ }^{43}$

\section{B. Historical Abuses and Current Research Participant Protections}

Although biomedical research is responsible for a vast array of medical advances, biomedical research has also been a means through which horrific abuses have been perpetrated in the name of acquiring knowledge. Nazi doctors conducted appalling research on prisoners without their consent. ${ }^{44}$ For four decades, the U.S. government studied the natural progression of untreated syphilis in poor, rural, African-American men in Tuskegee, Alabama, who thought they were receiving free healthcare from the U.S. government. ${ }^{45}$ U.S. government agencies conducted a number of experiments to test the effects of radiation on unknowing subjects. ${ }^{46}$ And as was recently uncovered, between 1946 and 1948, U.S. researchers infected prisoners and mental health patients in Guatemala with gonorrhea and syphilis to test the progression of the diseases. ${ }^{47}$

${ }^{43}$ See, e.g., President's COMM'N fOR ThE STUdy of Ethical Problems IN MEd. \& BIOMEDICAL \& BEHAVIORAL RESEARCH, COMPENSATING FOR RESEARCH INJURIES: THE ETHICAL AND LEgal IMPLiCATIONS OF PROGRAMS to REDRESS INJURED SubJeCts 89 (1982) [hereinafter PRESIDENT'S COMM'N] ("The focus of traditional (negligence) tort doctrine on the immediate parties to an accident - the victim and the allegedly negligent defendant-fits the moral equation of research injuries only imperfectly. The immediate parties-subject and investigator-encompass only one aspect of the wider society's interest in biomedical and behavioral research.").

${ }_{44}$ Prisoners were thrown into freezing water to calculate how long humans could withstand cold; they were subjected to malaria, mustard gas, and poison; they were subjected to forced sterilization; and they were put into pressurized chambers that resulted in either death from the pressure or execution for brain vivisection. See, e.g., Telford Taylor, Opening Statement of the Prosecution, December 9, 1946, in THE NAZI Doctors AND THE NUREMBERg CODE: HuMAN Rights in HumaN EXPERIMENTATION 67 passim (George J. Annas \& Michael A. Grodin eds., 1995).

${ }^{45}$ See, e.g., U.S. Public Health Service Syphilis Study at Tuskegee - The Tuskegee Timeline, CTRS. FOR DISEASE CONTROL \& PREVENTION, http://www.cdc.gov/tuskegee/timeline.htm (last updated June 15, 2011). Tests were conducted on 400 impoverished African-American males, and the research continued long after penicillin was known to be an effective cure. Elaborate ruses were put in place to keep the research participants uninformed about medical advances and their health status. The study was not shut down until 1972, when its existence was leaked to the press, forcing the researchers to stop in the face of public outcry. See, e.g., Shamim M. Baker, Otis W. Brawley \& Leonard S. Marks, Effects of Untreated Syphilis in the Negro Male, 1932 to 1972: A Closure Comes to the Tuskegee Study, 2004, 65 UROLOGY 1259 passim (2005).

${ }^{46}$ These experiments included injecting radioactive substances into babies and pregnant women, feeding radioactive material to mentally disabled children, and releasing radioactive materials over U.S. cities to simulate the effects of radioactive fallout. See, e.g., ADVISORY COMM. ON HUMAN RADIATION EXPERIMENTS, FINAL REPORT (1995), available at http://ia700402.us.archive.org/ $10 /$ items/advisorycommitte00unit/advisorycommitte00unit.pdf.

${ }^{47}$ See, e.g., Reverby, supra note 10 . The U.S. government has since formally apologized for its role in some of these experiments. See, e.g., Remarks in Apology to African-Americans on the Tuskegee Experiment, 33 WEEkLY COMP. PRES. DoC. 718 (May 16, 1997), available at http://www.gpo.gov/fdsys/pkg/WCPD-1997-05-19/pdf/WCPD-1997-05-19-Pg718.pdf; Press Release, HHS Press Office, Joint Statement by Secretaries Clinton and Sebelius on a 1946-1948 Study (October 1, 2010), available at http://www.hhs.gov/news/press/2010pres/10/20101001a.html. But, many participants received neither compensation nor acknowledgment of what had been done to them. See, e.g., Matthew T. Lee \& Jeannine A. Gailey, Attributing Responsibility for Organizational Wrongdoing, in INTERNATIONAL HANDBOOK OF WHITE-COLLAR AND CORPORATE CRIME 50, 62 (Henry N. Pontell \& Gilbert Geis eds., 2007). 
Because of the potential for abuse, biomedical research has become a more tightly regulated enterprise over the past half-century. ${ }^{48}$ In 1947 , the Nazi-era violations gave rise to the Nuremberg Code, ${ }^{49}$ the first generally accepted international code governing research with human subjects. Created by a judicial panel with input from physician advisors, the Nuremberg Code set forth the fundamental principle that the "voluntary consent of the human subject is absolutely essential." 50 The Nuremberg Code also set forth other requirements for conducting ethical research, including that research should be able to "yield fruitful results for the good of society," physical and mental suffering,"52 and that the degree of risk "should never exceed that determined by the humanitarian importance of the problem to be solved by the experiment." 53

Over time, the requirements of the Nuremberg Code came to be considered overly formalistic and inflexible, ${ }^{54}$ and the World Medical Association drafted a new set of guidelines. In 1964, the World Medical Association published the Declaration of Helsinki, a statement of ethical principles to guide physicians and other participants in medical research that involves human subjects. ${ }^{55}$ Although very much in keeping with the principles of the Nuremberg Code, the Declaration of Helsinki allowed research to be conducted on those incapable of providing informed consent in certain circumstances. ${ }^{56}$ The Declaration of Helsinki is widely regarded as a cornerstone of human research ethics. ${ }^{57}$

In the wake of revelations uncovered about the Tuskegee syphilis experiment in 1972, the United States turned its attention to the ethics of biomedical research within its borders and appointed a National Commission for the Protection of Human Subjects of Biomedical and Behavioral Research (the "National Commission") ${ }^{58}$ In 1979 , the National Commission produced the Belmont Report, which contained a set of ethical principles designed to "provide an analytical

${ }^{48}$ See, e.g., J.V. McHale, Law and Clinical Research - From Rights to Regulation? An English Perspective, 32 J.L. MED. \& ETHICS 718, 718 (2004) ("The last half century has been characterized by a growth in the regulation of clinical research nationally and internationally.").

${ }^{49}$ The Nuremburg Code, in THE NAZI Doctors AND THE NuREMBERg Code: Human Rights in HUMAN EXPERIMENTATION, supra note 44, at 2.

${ }^{50}$ Id. $\S 1$.

${ }^{51} I d . \S 2$.

52 Id. $\$ 4$.

${ }^{53}$ Id. $\S 6$.

${ }^{54}$ Particularly, the seemingly absolute requirement of informed consent left little room for experiments involving children, the mentally ill, and individuals in emergency situations. See, e.g., Grimes v. Kennedy Krieger Inst., Inc., 782 A.2d 807, 836 (Md. 2001) ("[P]hysician groups tended to find the Code too 'legalistic' and irrelevant to their therapeutic experiments, and set about to develop an alternative code to guide medical researchers.") (quoting George J. Annas, Mengele's Birthmark: The Nuremberg Code in United States Courts, 7 J. CONTEMP. HEALTH L. \& POL'Y 17, 19-21 (1991)) (internal quotation marks omitted).

55 WORLD MED. ASS'N, supra note 34; WORLD MED. ASS'N, DEClaration OF HELSINKI: ETHICAL PRINCIPLES FOR MEdiCAL RESEARCH INVOLVING HUMAN SUBJECTS (2008), available at http://www.wma.net/en/30publications/10policies/b3/index.html.pdf?print-media-type \& footerright $=[$ page $] /[$ toPage $]$.

${ }_{56}^{6}$ See WORLD MED. Ass'N, supra note $34, \S$ II.1.

${ }^{57}$ See, e.g., Snezana Bosnjak, The Declaration of Helsinki - The Cornerstone of Research Ethics, 9 ARCHIVE ONCOLOGY 179, 180 (2001). Though the Declaration of Helsinki has its detractors, it has also been considered the "most successful and influential" code. Grimes, 782 A.2d at 836.

${ }^{58}$ See U.S. Public Health Service Syphilis Study at Tuskegee - Research Implications, CTRS. FOR Disease CONTROL \& PrEvention, http://www.cdc.gov/tuskegee/after.htm (last updated June 15, 2011). 
framework [to] guide the resolution of ethical problems arising from research involving human subjects." 59 The National Commission's more concrete proposals, including a focus on informed participant consent and prior ethical review by institutional review boards (IRBs), became enshrined in federal regulations that formed the basis of the "Basic Policy for the Protection of Human Subjects" (known as the "Common Rule"), ${ }^{60}$ a rule that today governs the conduct of research undertaken by most federal agencies. ${ }^{61}$ The Common Rule and the Belmont Report together provide the backbone of the federal oversight system in the United States. ${ }^{62}$

More recently, ethical guidance has focused on the globalization of biomedical research and the concern that research may move to countries where regulation and participant protections are more lax. In 1993, the Council for International Organizations of Medical Sciences (CIOMS), in collaboration with the World Health Organization (WHO), produced the International Ethical Guidelines for Biomedical Research Involving Human Subjects, ${ }^{63}$ which includes additional requirements to render international research ethical. ${ }^{64}$ Most recently, the International Conference on Harmonization of Technical Requirements for Registration of Pharmaceuticals for Human Use, in conjunction with the WHO, promulgated the "Good Clinical Practice" (ICH/GCP) standards with the aim of harmonizing the regulation of clinical trials. ${ }^{65}$

These ethical guidelines and legal requirements have generally coalesced around a number of important protections for research participants. ${ }^{66}$ Research must be scientifically valid and able to answer the question it asks; subjecting research participants to risks is otherwise unjustifiable. ${ }^{67} \mathrm{~A}$ trial should be allowed to proceed only if the potential risks to participants are minimized, and if the potential benefits to individual participants and society justify the risks. ${ }^{68}$ Each participant must be

\footnotetext{
${ }^{59}$ Belmont Report: Ethical Principles and Guidelines for the Protection of Human Subjects of Research, Report of the National Commission for the Protection of Human Subjects of Biomedical and Behavioral Research, 44 Fed. Reg. 23,192, 23,193 (Apr. 18, 1979) (codified at 45 C.F.R. pt. 46 (2010))

${ }^{60}$ See Subpart A - Basic HHS Policy for Protection of Human Research Subjects, 45 C.F.R. pt. $46(2010)$.

${ }^{61}$ EMANUEL ET AL., supra note 9, at 27.

${ }^{62}$ See, e.g., Tom L. Beauchamp, Assessing the Belmont Report, APA NewsLs.: NewSL. ON PHIL. \& MED., Spring 2006, at 3 (noting that the Belmont Report "is one of the few documents that has influenced almost every sphere of activity in bioethics[,]" and its principles "became the backbone of federal law governing research involving human subjects"). Proposed modifications to the Common Rule have been proposed in an advanced notice of proposed rulemaking. See Human Subjects Research Protections: Enhancing Protections for Research Subjects and Reducing Burden, Delay, and Ambiguity for Investigators, 76 Fed. Reg. 44,512 (proposed July 26, 2011) (to be codified at 45 C.F.R.pt. 46). These modifications seek to streamline the regulation of multi-site research and do not address the issue of compensation for research-related injuries.

${ }^{63}$ COUNCIL For INT'L ORgs. OF MED. Scis. \& THE WORLd Health Org., InTERnational ETHICAL GUIDELINES FOR BIOMEDICAL RESEARCH INVOLVING HUMAN SUBJECTS (1993) [hereinafter CIOMS (1993)]. The guidelines were updated in 2002. CIOMS (2002), supra note 34.

${ }^{64}$ One such requirement is that research must be "responsive to the health needs and the priorities of the community in which it is to be carried out." See CIOMS (2002), supra note 34, at 51.

${ }^{65}$ See International Conference on Harmonisation; Good Clinical Practice: Consolidated Guideline; Availability, 62 Fed. Reg. 25,692 (May 9, 1997).

${ }^{66}$ See, e.g., Ezekiel J. Emanuel, David Wendler \& Christine Grady, What Makes Clinical Research Ethical?, 283 JAMA 2701, 2701 (2000); Markus Schott, Medical Research on Humans: Regulation in Switzerland, the European Union, and the United States, 60 FOOD \& DRUG L.J. 45,69 (2005) ("One of the most striking features of the examined legal sources is the high degree of similarity among them.").

${ }^{67}$ Emanuel, Wendler \& Grady, supra note 66, at 2704.

${ }^{68}$ Id. at 2705.
} 
given sufficient information about the research to "make a voluntary and uncoerced decision whether to participate," though exceptions exist for children and individuals otherwise unable to give consent. ${ }^{69}$ Research proposals must be submitted and reviewed in advance by a research ethics committee with authority to prevent trials that do not satisfy these ethical requirements from going forward. ${ }^{70}$ And research participants must be allowed to stop participating at any time.

Despite the proliferation of guidance documents, a serious gap in ensuring research participant protection remains. These guidance documents are, for the most part, silent about obligations owed to research participants once injury occurs. ${ }^{71}$ Regardless of how tightly regulated the research enterprise is, injuries will still occur; merely informing participants about potential future injuries provides little comfort once injuries do occur. Two organizations-CIOMS and the Institute of Medicine-have taken the lead in recommending that injured research participants receive compensation. ${ }^{72}$ But as long as the issue of compensating injured research participants remains unaddressed under U.S. law, a critical gap in research participant protection remains.

\section{National Advisory COMmittees Consider Compensating InJured RESEARCH PARTICIPANTS}

For nearly forty years, U.S. national advisory committees have considered whether there is an obligation to compensate injured research participants. These committees have concluded repeatedly that compensating injured research participants is morally required, and that the tort system is inadequate to ensure compensation. ${ }^{73}$ But, these advisory committees have put forth no concrete proposals, and have taken no steps to implement systematic compensation. ${ }^{74}$ The changing legal and global research landscapes render further inaction morally indefensible and an impediment to the research enterprise.

Although the issue of compensating injured research participants was considered by the U.S. government as far back as $1940,{ }^{75}$ the first national advisory committee to address the issue was a 1973 ad hoc panel created by the Department

${ }^{69} \mathrm{Id}$. at 2706 .

${ }^{70}$ See Criteria for IRB Approval of Research, 45 C.F.R. § 46.111(a) (2010) (noting that IRBs ensure that risks to subjects are minimized, that risks to subjects are reasonable in relation to anticipated benefits, that selection of subjects is equitable, and that informed consent is sought and documented). In many institutions, research is subject to scientific review by a committee tasked with ensuring sufficient scientific merit. See, e.g., Scientific Review Committees, AM. HEalth Assist ANCE Found., http:/www.ahaf.org/aboutahaf/structure/src.html (last updated Sept. 23, 2011). Trials are subject to continuing review of adverse events and interim findings. See IRB Review of Research, 45 C.F.R. $\$ 46.109$ (e) (2010). Many trials are also reviewed by data monitoring committees that monitor incoming data and assess patient safety and efficacy of the intervention while the trial is ongoing.

${ }^{71}$ See generally supra notes 49, 55, 59, 60, 65; CIOMS (1993), supra note 63.

${ }^{72}$ See CIOMS (2002), supra note 34, at 78 ("Investigators should ensure that research subjects who suffer injury as a result of their participation are entitled to free medical treatment for such injury and to such financial or other assistance as would compensate them equitably for any resultant impairment, disability or handicap."); INST. OF MED., RESPONSIBLE RESEARCH: A SYSTEMS APPROACH TO PROTECTING RESEARCH PARTICIPANTS 193 (2002) ("Organizations conducting research should compensate any research participant who is injured as a direct result of participating in research, without regard to fault.").

${ }^{73}$ See infra note 112 .

${ }^{74}$ See infra note 112.

${ }^{75}$ In the 1940s, the Army debated, but ultimately rejected, suggestions to compensate prisoner volunteers injured during malaria and hepatitis experiments. ADVISORY COMM. ON HUMAN RADIATION EXPERIMENTS, supra note 46 , at 827. 
of Health, Education, and Welfare to review the Tuskegee syphilis study. ${ }^{76}$ Several subsequent committees-including the 1977 Department of Health, Education, and Welfare Task Force on the Compensation of Injured Research Subjects; ${ }^{77}$ the 1978 National Commission for the Protection of Human Subjects of Biomedical and Behavioral Research; ${ }^{78}$ the 1982 President's Commission for the Study of Ethical Problems in Medicine and Biomedical and Behavioral Research (the "1982 President's Comission"); ${ }^{79}$ the 1995 Advisory Committee on Human Radiation Experiments; ${ }^{80}$ and the 2001 National Bioethics Advisory Commission ${ }^{81}$-have also considered the issue. The issue of compensating injured research participants was most recently addressed in 2011 by the Presidential Commission for the Study of Bioethical Issues. $^{82}$

These committees repeatedly found a moral obligation to compensate injured research participants, ${ }^{83}$ concluding that those "who are harmed as a result of participating in research ought to receive some compensation for their injuries," 84 and that a mechanism to compensate injured research participants "has long been justified on ethical grounds. ${ }^{" 85}$ Alan Weisbard, an attorney who served with the 1982 President's Commission, noted the "obvious intuitive justice and rightness of taking care of those who volunteered to undergo risky procedures for the common good, and through no fault of their own-or of anyone else-were seriously injured in the process." ${ }^{86}$ This intuition was best articulated as a justification for compensating injured research participants by the 1982 President's Commission:

${ }^{76}$ See Pub. Health SerV., U.S. Dep'T of Health, Educ. \& Welfare, Final Report of the TUSKEGEE SYPHILIS STUDY AD HOC ADVISORY PANEL 123 (1973), available at http://www.research.usf.edu/cs/library/docs/finalreport-tuskegeestudyadvisorypanel.pdf.

${ }^{77}$ SEC'Y'S TASK FORCE ON THE COMP. OF INJURED RESEARCH SUBJECTS, U.S. DEPT. OF HEALTH, EDUC. \& WELFARE, REPORT OF THE TASK FORCE (1977) [hereinafter SECRETARY'S TASK FORCE].

${ }^{78}$ Institutional Review Boards: Report and Recommendation of the National Commission for the Protection of Human Subjects of Biomedical and Behavioral Research, 43 Fed. Reg. 56,174 (Nov. 30, 1978).

${ }^{79}$ PRESIDENT'S COMM'N, supra note 43.

${ }^{80}$ ADVISORY COMM. ON HUMAN RADIATION EXPERIMENTS, supra note 46.

${ }^{81}$ NAT'l BIOETHICS ADVISORY COMM'N, ETHICAL AND POLICY ISSUES IN RESEARCH INVOLVING HUMAN PARTICIPANTS 125 (2001).

82 PResidential COMM'N For the Study OF BIOETHiCal IsSues, MORAL SCIENCE: Protecting Participants in Human Subjects Research (2011) [hereinafter Presidential COMM'N].

${ }^{83}$ See, e.g., Opening Letter to PRESIDENT's COMM'N, supra note 43 (acknowledging "the ethical obligation toward subjects"); SECRETARY'S TASK FORCE, supra note 77, at VI-6 ("[T] [he [federal government's] compensatory obligation extends at least to injured volunteers ... sponsored by and for the benefit of society as a whole.").

${ }^{84}$ PRESIDENT'S COMM'N, supra note 43 , at 1 .

${ }^{85}$ NAT'L BIOETHICS ADVISORY COMM'N, supra note 81, at 123.

${ }^{86}$ Alan J. Weisbard, The Role of Philosophers in the Public Policy Process: A View from the President's Commission, 97 ETHICS 776, 780 (1987). 
Medical and scientific experimentation, even if carefully conducted, carries certain inherent dangers. Experimentation has its victims, people who would not have suffered injury and disability were it not for society's desire for the fruits of research. Society does not have the privilege of asking whether this price should be paid; it is being paid. In the absence of a program of compensation of subjects, those who are injured bear both the physical burdens and the associated financial costs. The question of justice is why it should be those persons, rather than others, who are to be expected to absorb the financial, as well as the unavoidable human costs of the societal research enterprise which benefits everyone. ${ }^{87}$

These committees, along with bioethics commentators, have argued forcefully that compensating injured research participants is justified by principles of: (1) distributive justice; (2) compensatory justice; (3) internalization of true costs; and (4) the need to maintain trust in the research enterprise. ${ }^{88}$

The first Task Force that considered the issue concluded that compensating injured research participants was a matter of distributive justice, an obligation to distribute the benefits and burdens of research equitably. ${ }^{89}$ Prior to beginning a research trial, sponsors of research are able to determine whether the foreseeable benefits of research outweigh the burdens. ${ }^{90}$ Research participants are less wellequipped to make this determination. ${ }^{91}$ As discussed below, participants are less able to understand the risks and benefits of research and cannot know certain information, e.g., that they will be among the small percentage of research participants who will be injured by the research. Shifting benefits from those who are ensured an appropriate benefit to those who have been unexpectedly and disproportionately burdened by injury satisfies the dictates of distributive justice.

The 1977 Task Force also argued that compensation should be provided as a matter of compensatory justice, an obligation to make whole one you have injured. ${ }^{92}$ Compensatory justice requires that an attempt be made to restore injured research participants to their previous condition. ${ }^{93}$ The obligation can be satisfied by providing medical care when it is possible to restore injured persons to their previous state, or by monetary compensation when literal restoration is not feasible.

${ }^{87}$ PRESIDENT'S COMM'N, supra note 43 , at 50.

${ }^{88}$ See, e.g., SECRETARY'S TASK FORCE, supra note 77 , at VI.

${ }^{89}$ See, e.g., id. (noting that the "principle of distributive justice" could justify compensating injured research participants: "[S]ince society is the beneficiary of biomedical and behavioral research, it ought to bear the burden of biomedical and behavioral research injuries as well"). See also PRESIDENTIAL COMM'N, supra note 82, at 63 ("Thus, treatment or compensation/restitution for the costs of treatment, is justified by distributive or corrective justice and by duties of beneficence."). Scholars have also used the principle of distributive justice to justify compensating injured research participants. See, e.g., David B. Resnik, Compensation for Research-Related Injuries: Ethical and Legal Issues, 27 J. LEGAL MED. 263 (2006).

${ }^{90}$ See Resnik, supra note 89 , at 282-83.

${ }^{91}$ See id. at 282.

92 See, e.g., SECRETARY'S TASK FORCE, supra note 77, at VI-3 ("[S]ociety, through its governmental agents, has intervened in the lives of the injured individuals, and therefore society may be said to have an obligation to repair (so far as is possible) injury done to individuals ...."). See also PRESIDENTIAL COMM'N, supra note 82, at 63 ("Thus, treatment or compensation/restitution for the costs of treatment, is justified by distributive or corrective justice and by duties of beneficence.").

${ }^{93}$ See, e.g., SECRETARY'S TASK FORCE, supra note 77, at VI-4 (defining compensatory justice as the "form of justice which seeks to redress injury even when no fault or blame is associated with the injury"). 
A third justification for compensation is that it forces those conducting research, who can best manage and mitigate the risk of injury, to internalize the true costs of research. The Tuskegee Syphilis Study Ad Hoc Advisory Panel adopted Guido Calabresi's arguments that requiring compensation for research-related injuries "causes the full cost of research in humans to be placed on the research center," which "may cause those involved in the most risky or least useful [research] to consider carefully whether the experiment is worth it, whether it is best done by those who propose to do it, and whether there is an alternative, and safer, way of obtaining approximately the same results." 94 Requiring compensation forces sponsors of research to weigh the true costs of research in determining what research to conduct and what systems to put in place to best manage the associated risks. ${ }^{95}$

Finally, the Institute of Medicine published a report in which it argued that compensating injured research participants fosters trust in the research enterprise. The research enterprise depends upon continued participant enrollment in research. Forcing injured research participants to bear both the medical and financial burdens of research-related injuries could lead to "diminished public trust in the research community," and could lead future generations to refuse to participate in research. ${ }^{96}$

The advisory committees have also addressed the counterargument that compensation may not be required because research participants assume and accept risk through the informed consent process. ${ }^{97}$ Under this counterargument, because research participants agree through the informed consent process to accept the articulated risks, mandating compensation protects individuals in ways they have decided is unnecessary. ${ }^{98}$

Advisory committees have disputed any characterization of informed consent as "a waiver of a moral right to compensation." "99 Advisory committees have noted that viewing the informed consent process as a waiver of a right to compensation is an overly legalistic view of the role of informed consent. The purpose of informed consent is to ensure that individuals control whether or not they participate in research and that any decision to participate is voluntary and uncoerced. ${ }^{100}$ This

${ }^{94}$ Pub. Health Serv., supra note 76, at 41-42.

${ }^{95}$ This is closely related to the economic concept of risk-spreading, that the person who can best and most efficiently afford the costs of injury should bear them. According to Wendy Mariner, economic theory favors shifting the costs of research-related injuries to research sponsors, who have greater resources than individual injured research participants and can recover financial losses through revenue-generating mechanisms. See Wendy K. Mariner, Compensation for Research Injuries, in 2 WOMEN AND HEALTH RESEARCH: ETHICAL AND LEGAL ISSUES OF INCLUDING WOMEN IN CLINICAL STUDIES 113, 114 (Inst. of Med. ed., 1994).

${ }^{96}$ INST. OF MED., supra note 72, at 14-15. See also PRESIDENTIAL COMM'N, supra note 82, at 61 ("Potential human research subjects may be more likely to agree to serve if they know they will be taken care of in the event that they are harmed as a direct result of their participation. In an era in which the recruitment of adequate numbers of research subjects continues to be a major challenge, this could be significant."). This is not an idle concern. The fallout from the Tuskegee research experiments left wide swaths of the population unwilling to participate in research and untrusting of the medical establishment in general. Stephen B. Thomas \& Sandra Crouse Quinn, The Tuskegee Syphilis Study, 1932 to 1972: Implications for HIV Education and AIDS Risk Education Programs in the Black Community, 81 AM. J. PUB. HEALTH 1498, 1498 (1991).

${ }^{97}$ This counterargument is also articulated in Mariner, supra note 95, at 116.

${ }^{98}$ See id.

99 SECRETARY'S TASK FORCE, supra note 77 , at VI-7.

${ }^{100}$ See, e.g., id. at VI-5 ("Informed consent in the research setting functions as a recognition of a protection for a person's integrity and autonomy, but does not imply a waiver of the right of the person to compensation in the event of injury."); Childress, supra note 32, at 25 ("The requirement of consent is based on faimess and respect for the autonomy of persons."); Emanuel, Wendler \& Grady, 
voluntary and uncoerced decision to participate should not act as a legal waiver, ${ }^{101}$ and, in fact, the federal research regulations expressly provide that research participants cannot be made to waive their legal rights in the informed consent process. ${ }^{102}$

Second, any argument that respect for persons' autonomous decision-making counsels against compensating injured research participants mistakenly conflates participants' willingness to sign informed consent documents without demanding compensation with a preference not to receive compensation. ${ }^{103}$ Participants may sign informed consent documents accepting risk and foregoing compensation because those are the terms presented to them. ${ }^{104}$ That does not mean that participants prefer to go uncompensated in the event of research-related injuries; it simply means that participants are willing to accept the terms presented, ${ }^{105}$ that participants were unaware that they could negotiate for mandated compensation, ${ }^{106}$ or that participants did not realize that they may not receive compensation. ${ }^{107}$

Third, research participants may not actually understand the risks and benefits that they accept by agreeing to participate in research. Research risks often include remote possibilities of medical complications, the likelihood and consequences of which may be difficult to assess. ${ }^{108}$ Research also carries the potential for unforeseen risks to materialize such that it may be impossible for research participants to consent to all risks of research. ${ }^{109}$ Research participants also may misunderstand the benefits that they receive from participating in research. ${ }^{110}$ Given that participants

supra note 66, at 2706 ("Informed consent embodies the need to respect persons and their autonomous decisions.").

${ }^{101}$ See, e.g., INST. OF MED., supra note 72, at 191 ("It has been argued that a participant relinquishes his or her right to compensation when giving informed consent, but in the committee's view, a right to compensation for research-related injury should not be subject to waiver."); SECRETARY'S TASK FORCE, supra note 77, at VI-5 ("[I]nformed consent does not negate or waive the obligation to provide compensation."); Childress, supra note 32 , at 25 ("[W]hile consent is a necessary moral condition for ethically justified research in normal circumstances, ... [i]ts presence does not remove society's moral obligation of compensatory justice...."). Regulations governing research expressly forbid informed consent documents from requiring research participants to waive legal rights. See General Requirements for Informed Consent, 45 C.F.R. $\S 46.116$ (2011).

${ }^{102}$ For the general requirements for informed consent, see 45 C.F.R. $\S 46.116$ ("No informed consent, whether oral or written, may include any exculpatory language through which the subject or the representative is made to waive or appear to waive any of the subject's legal rights ....").

${ }^{103}$ See, e.g., SECRETARY'S TASK FORCE, supra note 77, at VI-7 ("Volunteers for experimentation have a reasonable interest in requiring compensation as a condition for participation in an experiment. It is the type of debt a volunteer should require from a researcher.").

104 See NAT'L BIOETHICS ADVISORY COMM'N, supra note 81, at 123-24 (noting that OHRP provides guidance for researchers to craft noncompensatory language without running afoul of the ban on exculpatory clauses).

${ }^{105}$ It may also signify that participants do not fully understand their rights. Studies have shown that the reading level of an average research participant is sixth to eighth grade; the average informed consent document is written at a tenth grade reading level; and the section pertaining to compensation is written at an even higher level. See Resnik, supra note 89, at 270.

${ }^{106}$ Given that informed consent language and research procedures are approved by IRBs, research participants may not actually have the power to negotiate for compensation.

${ }^{107}$ The language in most informed consent documents-that participants do not surrender their legal rights by participating in research-is confusing at best.

${ }^{108}$ See, e.g., G. Owen Schaefer \& Alan Wertheimer, The Right to Withdraw from Research, 20 KENNEDY INST. ETHICS J. 329, 338 (2010).

${ }^{109}$ See, e.g., NAT'L BIOETHICS ADVISORY COMM'N, supra note 81, at 123 ("[E]ven if consent forms and the disclosures within them are comprehensive, completely unforeseen iatrogenic harms might occur in research.").

${ }^{110}$ A substantial proportion of participants confuse the treatment they receive in research with that of standard medical care. Sam Horng \& Christine Grady, Misunderstanding in Clinical Research: 
may not understand the sacrifices that they make by participating in research, it is important not to foreclose compensation in the event of research-related injuries.

Although most advisory committees have ultimately recommended systematic no-fault compensation, ${ }^{111}$ none set forth concrete proposals or took steps toward implementing no-fault compensation. ${ }^{112}$ Some committees also recommended a smaller step viewed as the necessary precursor to systematic compensation: ${ }^{113}$ collecting empirical data about the necessity and feasibility of compensating injured research participants. ${ }^{114}$ Progress has not been made on this front either. ${ }^{115}$ Thus, despite recognition for four decades of a moral obligation to compensate injured research participants, the United States only requires that participants be informed as to whether care or compensation will be available. ${ }^{116}$ Research participants may end up being forced to choose between bearing the medical and financial costs of research-related injuries alone ${ }^{117}$-in some cases with the help of their

Distinguishing Therapeutic Misconceptions, Therapeutic Misestimation \& Therapeutic Optimism, 25 IRB: ETHICS \& HUM. RES. 11, 12 (2003). Despite being informed about study design implications, including random assignment to a control or comparison group, research participants may still believe that every aspect of research is designed for personal benefit. See, e.g., id.; Amulya Mandava et al., Mapping the Landscape: The Data on Informed Consent, 38 J. MED. ETHICs (forthcoming 2012) (finding substantial variation in participant understanding of research in both developing and developed countries, particularly with regard to randomization, placebo-controlled designs, and side effects); Litton \& Miller, supra note 16, at 572.

${ }^{11}$ See, e.g., ADVISORY COMM. ON HUMAN RADIATION EXPERIMENTS, supra note 46, at 528 ("The Advisory Committee recommends . . . a mechanism for the satisfactory resolution of this longstanding social issue."); NAT'L BIOETHICS ADVISORY COMM'N, supra note 81, at 123 ("A comprehensive system of oversight of human research should include a mechanism to compensate participants for medical and rehabilitative costs resulting from research-related injuries."); SECRETARY'S TASK FORCE, supra note 77, at II-2 ("Human subjects who suffer physical, psychological, or social injury ... should be compensated ...."); PUB HEALTH SERV., supra note 76, at 41 ("An insurance plan should be devised and implemented for the compensation of subjects harmed as a consequence of their participation in research activities.").

112 See, e.g., PresidenTial COMM'N, supra note 82 , at 70 ("The Commission recognizes that previous presidentially appointed bioethics commissions and other duly appointed advisory bodies have made similar recommendations regarding compensation or treatment for research-related injuries; yet no clear response by the federal government has been issued.").

${ }_{113}$ See, e.g., id. at 125 (noting that the Federal Government would not implement a proposal "[i]n the absence of a finding that a significant number of modern research subjects are unfairly denied compensation"); SECRETARY'S TASK FORCE, supra note 77, at III-2 (explaining that past no-fault proposals had not been accepted due to a lack of data).

${ }^{114}$ See, e.g., ADVISORY COMM. ON HUMAN RADIATION EXPERIMENTS, supra note 46, at 528 ("The Advisory Committee recommends that the Human Radiation Interagency Working Group review the area of compensation for research injuries ...."); NAT'L BIOETHICS ADVISORY COMM'N, supra note 81 , at 125 ("More information is needed about the nature and extent of research-related injuries and uncompensated research injuries."); Opening Letter to PRESIDENT's COMM'N, supra note 43 ("To determine the need for, and practical feasibility of, a compensation program, the Commission recommends that a small experiment be undertaken over a three to five-year period."); SECRETARY'S TASK FORCE, supra note 77, at VI-1 to VI-2; PRESIDENTIAL COMM'N, supra note 82, at 67-69.

115 See, e.g., ADVISORY COMM. ON HUMAN RADIATION EXPERIMENTS, supra note 46, at 528 ("No policy exists even today ...."); NAT'L BIOETHICS ADVISORY COMM'N, supra note 81, at 125 ("The availability, circumstances, and procedures for compensating injured research participants have remained unchanged from those observed by the Tuskegee Advisory Panel."); Pub HealTH SERV., supra note 76, at 23 ("No policy for the compensation of research subjects harmed as a consequence of their participation in research has been formulated."); PRESIDENTIAL COMM'N, supra note 82, at 70. (2005).

${ }_{16}$ See Basic HHS Policy for Protection of Human Research Subjects, 45 C.F.R. $\S 46.116$ (a)

${ }^{117}$ See, e.g., NAT'L BIOETHICS ADVISORY COMM'N, supra note 81 , at 125-26 ("[I]njured research participants alone bear both the cost of lost health and the expense of medical care .... [T] he costs of research injuries should not be borne by the injured participants ...."). 
insurance ${ }^{118}$ - or bringing suit to recover for their injuries in a legal system illequipped to ensure adequate protection. ${ }^{119}$

In the past decade, the legal landscape and the global research landscape have changed considerably. In light of these developments, described in Parts III and IV, continued inaction toward compensating injured research participants has become morally indefensible and practically unsustainable.

\section{CONTINUED RELIANCE ON THE TORT SYSTEM TO COMPENSATE INJURED RESEARCH PARTICIPANTS IS MORALLY INDEFENSIBLE}

The trend in biomedical research over the past half-century has been towards increasing protections for research participants, generally in the form of informed consent and prior review by research ethics committees. Despite strong philosophical justifications for requiring compensation, and recognition of a moral obligation to compensate injured research participants by national advisory committees, the United States has never required that injured research participants receive compensation. ${ }^{120}$ Accordingly, most research institutions do not provide compensation, either in the form of free medical care or financial compensation, ${ }^{121}$ and research participants who suffer research-related injuries may be forced to bear the medical and financial burdens of research-related injuries alone. ${ }^{122}$

Instead, the United States has continued to rely on the tort system as the primary mechanism through which injured research participants receive compensation. As set forth below, the tort system is a problematic mechanism for ensuring that injured research participants receive compensation. The tort system is generally problematic in ways that have been addressed in detail elsewhere: the tort system is timeconsuming, adversarial, expensive, and has a tendency to under-compensate most injured participants while over-compensating a select few. ${ }^{123}$

The tort system also poses challenges that are unique to injured research participants, particularly when compared to injured medical patients. Injured research participants have more difficulty than medical patients showing that a duty owed to them was breached; that the intervention caused their injury; and that they

${ }^{118}$ See infra notes $132-37$ and accompanying text.

119 See, e.g., NAT'L BIOETHICS ADVISORY COMM'N, supra note 81, at 125 ("[E]ven when warranted and successful, such lawsuits are costly and slow and thus are of limited value at the time the injury is incurred."); PRESIDENT's COMM'N, supra note 43, at 88 ("But if research subjects should, on ethical grounds, be compensated for their injuries, despite the lack of negligence by an investigator, the rules of negligence law will be patently inappropriate."); SECRETARY's TASK FORCE, supra note 77, at V-2 ("Given the fact that the very nature of research is a venture into the unknown, it is unlikely that harm resulting from effects that were not reasonably foreseeable would be a basis for liability, and adequately drafted consent forms would likely obviate liability for anticipated risks."); PUB HEALTH SERV., supra note 76, at 36-37 ("Those subjects whose injury does result from negligence are faced with the usual difficulties and uncertainties inherent in a lawsuit.").

${ }_{120}$ Sabina Gainotti \& Carlo Petrini, Insurance Policies for Clinical Trials in the United States and in Some European Countries, 1 J. CliniCAL Res. \& BIOETHICS 1, 2-3 (2010).

${ }^{121}$ For more information about institutional compensation policies, see the discussion and data included in supra Part II.A.

${ }_{122}$ See source cited supra note 117.

${ }^{123}$ See, e.g., INST. OF MED., supra note 72, at 190-91; R. Ian McEwin, No-Fault Compensation Systems, in ENCYCLOPEDIA OF LAW \& ECONOMICS $\$ 3600$, at 737, 739 (Boudewijn Bouckaert \& Gerrit De Geest eds., 1999), available at http://encyclo.findlaw.com/tablebib.html; Mariner, supra note 95, at 121; Jeffrey O'Connell, Tort Versus No-Fault: Compensation and Injury Prevention, 19 ACCIDENT ANALYSIS \& PREVENTION 63 (1987) ("The attempt to achieve a fair and rational method for the compensation of victims has been displaced by a form of litigation lottery."). 
did not, through the informed consent process, "assume the risk."124 Injured research participants are also often injured by unforeseen risks that are not anyone's fault and so fall outside the tort system entirely. ${ }^{125}$ Additionally, as set forth below, evolving and complex legal doctrines systematically deny access to the U.S. legal system for research participants injured while participating in federal research and for those participating in international research. Recent legal developments, including two decisions by the U.S. Court of Appeals for the Second Circuit ${ }^{126}$ and a lawsuit filed by those injured in the recently uncovered Guatemala research, ${ }^{127}$ emphasize the inadequacy of the tort system as a means of ensuring compensation for injured research participants.

\section{A. INJURED U.S. PARTICIPANTS RECEIVE No SYSTEMATIC COMPENSATION}

Current U.S. law does not require that injured research participants receive compensation. U.S. regulations require only that participants enrolled in research involving more than minimal risk receive an explanation as to whether, and to what extent, compensation or medical treatment will be available in the event of a research-related injury. ${ }^{128}$

A study commissioned by the Department of Health and Human Services found that most research institutions do not have formal policies to provide free care or compensation to injured research participants. ${ }^{129}$ Of the 129 policies reviewed, eighty-four percent of research institutions provided no free care or treatment to injured research participants. ${ }^{130}$ Not one of the 129 policies reviewed offered compensation for lost wages or pain and suffering. ${ }^{131}$

This is not to say that no injured research participants receive free medical care or compensation for their injuries; some institutions provide more than what is required by law. The leader in compensating injured research participants is the University of Washington, which has maintained a self-funded, no-fault compensation plan that has provided injured research participants with

\footnotetext{
${ }^{124}$ For more information and a discussion about assumption of risk, see infra note 161 and accompanying text.

${ }^{125}$ See Gainotti \& Petrini, supra note 120 , at 2.

${ }^{126}$ See Kiobel v. Royal Dutch Petroleum Co., 621 F.3d 111 (2d Cir. 2010); Abdullahi v. Pfizer, Inc., 562 F.3d 163 (2d Cir. 2009), cert denied, 130 S. Ct. 3541 (2010).

${ }^{127}$ See Reverby, supra note 10.

${ }^{128}$ See Basic HHS Policy for Protection of Human Research Subjects, 45 C.F.R. $\S 46.116(a)(6)$ (2005). For institutions that will not provide compensation or treatment, the Office of Human Research Protection suggests the following language: "This hospital makes no commitment to provide free medical care or payment for any unfavorable outcomes resulting from participation in this research. Medical services will be offered at the usual charge." "Exculpatory Language" in Informed Consent, OfFice for Human Research Prots., U.S. DeP'T OF Health \& Human SERvs. (Nov. 15, 1996), http://www.hhs.gov/ohrp/policy/exculp.html.

129 The Lewin Grp., TASK ORder No. 2: CARE/COMPENSATION fOR INJURIES IN Clinical RESEARCH ES-2 (2005)

${ }^{130} \mathrm{Id}$.

131 Id.; see also Gainotti \& Petrini, supra note 120 , at 3 (discussing a study conducted by Department of Health and Human Services that found that 51.2 percent of academic medical centers "provided no free care to the injured subjects"); Michael K. Paasche-Orlow \& Frederick L. Brancata, Assessment of Medical School Institutional Review Board Policies Regarding Compensation of Subjects for Research-Related Injury, 118 AM. J. MED. 175, 177 (2005) (finding that only one-half of research participants enrolled in research at medical schools have their medical bills for researchrelated injuries covered).
} 
reimbursement for medical costs since $1979 .{ }^{132}$ Other organizations, such as the Department of Veterans Affairs, ${ }^{133}$ the $\mathrm{NIH},{ }^{134}$ and the Department of Defense, ${ }^{135}$ have also voluntarily agreed to provide short-term medical care for injured research participants during the course of research trials. ${ }^{136}$ Since 2000 , Medicare has paid for care for medical complications that result from participation in "qualifying trials"therapeutic trials that enroll patients rather than healthy volunteers. ${ }^{137}$ But these and a few other institutions are the exception rather than the rule. The vast majority of research institutions provide no medical care or financial compensation for researchrelated injuries. ${ }^{138}$

Because injured research participants are not routinely provided medical care or compensated for research-related injuries, injured research participants often bear the medical and financial burdens of research-related injuries alone. Injured research participants with private health insurance may seek coverage of their medical bills through their insurer. ${ }^{139}$ But, private insurance provides only limited relief. It does not provide compensation for financial injuries, and may not provide compensation for injuries known to arise from experimental treatment. ${ }^{140}$ Moreover, those who are uninsured have no outlet for receiving systematic compensation for their injuries. ${ }^{141}$

${ }^{132}$ See Gainotti \& Petrini, supra note 120 , at 3. Under the plan, medical expenses are covered up to $\$ 10,000$, and other expenses, including economic losses, may also be covered. For a claim to proceed, the research participant must sign a document releasing the university from tort liability. See id.; Human Subjects Div., Univ. of Wash., Research Care Plan - Policy Summary and IMPLICATIONS (2008), available at http://wWw.washington.edu/research/hsd/docs/557; see also Human SubJects Div., Univ. of Wash., UW COMPENSATION Plan AdVERSE Flow Chart (2010), available at $\mathrm{http}: / / \mathrm{www}$.washington.edu/research/hsd/docs $/ 467$.

${ }^{133}$ See Treatment of Research-Related Injuries to Human Subjects, 38 C.F.R. $\S 17.85$ (1998) ("VA medical facilities shall provide necessary medical treatment to a research subject injured as a result of participation in a research project ....").

${ }^{134}$ See, e.g., Office of Human SubJects Research, NAT'L InStS. OF Health, Sheet 6GUIDELINES FOR WRITING INFORMED CONSENT DOCUMENTS I 4(s) (2006), available at http://ohsr.od.nih.gov/info/sheet6.html ("The Clinical Center of the NIH will provide short-term medical care for any injury resulting from your participation in research here. In general, no long-term medical care or financial compensation for research-related injuries will be provided ....").

${ }^{135}$ U.S. DeP'T OF DEF., DEPARTMENT OF DEFEnSE INSTRUCTION NuMBER 6000.8: Funding AND ADMINISTRATION OF CliNICAL INVESTIGATION PROGRAMS $\uparrow \quad 6.2 .4$ (2007), available at http://www.dtic.mil/whs/directives/corres/pdf/600008p.pdf ("All CIP investigators shall... for research involving more than minimal risk ... include in every intramural (in-house) CIP protocol an arrangement for treatment of any research-related injuries.").

${ }^{136}$ A discussion of these policies is presented in INST. OF MED., supra note 72 , at 188; THE LEWIN GRP., supra note 129, at 16-19; Gainotti \& Petrini, supra note 120, at 3; PRESIDENTIAL COMM'N, supra note 82, at 65 .

${ }^{137}$ Larry D. Scott, Research-Related Injury: Problems and Solutions, 31 J.L. MED. \& ETHICS $419,421-22(2003)$.

${ }^{138}$ See Gainotti \& Petrini, supra note 120, at 3; THE LEWIN GRP., supra note 129, at app. A.

${ }^{139}$ See, e.g., THE LEWIN GRP., supra note 129, at ES-3 ("In the absence of showing fault, in fact, insurance serves as the primary vehicle for compensation of such injuries in the United States.").

${ }^{140}$ See, e.g., NAT'L CANCER INST., NAT'L INSTS. OF HEALTH, Clinical Trials and Insurance Coverage, http://www.cancer.gov/clinicaltrials/payingfor/insurance-coverage (May 8, 2009) ("Even if you have health insurance, your plan may not cover all of the costs related to receiving treatment in a clinical trial. This is because some health insurance companies define clinical trials as "experimental."').

${ }_{141}$ This situation will change as additional provisions of the Patient Protection and Affordable Care Act come into force. Under section 10103(c) of the Patient Protection and Affordable Care Act, requirements are imposed on group health plans and health insurance issuers to provide for coverage of routine patient costs associated with approved clinical trials. The provision does not address research-related injuries. See Healthcare Reform Law May Impact Clinical Trial Billing and Contract Negotiations, MOSES \& SINGER LLP (May 2010), available at http://mosessinger.com/articles/ 
The remaining alternative is to turn to the tort system. As set forth below, this is an untenable solution.

\section{B. The Tort System Poses Serious Challenges for All Research PARTICIPANTS}

Because so few sponsors of research provide medical care or compensation for research-related injuries, and because individual health insurance provides only limited recourse, injured research participants often must turn to the tort system to be made whole. The tort system, as mentioned above, is an unsatisfactory compensation mechanism for almost all litigants - the tort system is timeconsuming, adversarial, expensive, and has a tendency to under-compensate most injured participants while over-compensating a select few. ${ }^{142}$ The tort system is uniquely difficult for injured research participants, even as compared with injured medical patients, in ways that have not been fully appreciated.

Unlike medical malpractice, which has a robust body of case law, there are very few reported cases dealing with research-related injury. ${ }^{143}$ A number of reasons have been given for this lack of case-law, including effective implementation of the informed consent process, the limited amount of damages potentially recoverable, and the increasing conduct of clinical trials abroad where the likelihood of a case going to trial may be lower than in the United States. ${ }^{144}$ Another key factor is the willingness of potential defendants to settle when presented with bad facts, a sympathetic plaintiff, or the potential for bad precedent. ${ }^{145}$ A key overlooked factor is the extent to which tort law principles make recovery for research-related injuries difficult.

Although some injured research plaintiffs have found legal success when armed with facts suggesting that no informed consent had been given at all, ${ }^{146}$ as might be

files/HealthcareReformLawClinicalTrials.pdf. Nevertheless, some currently uninsured individuals are likely to become insured as a result of the new policy measures.

${ }^{142}$ See sources cited supra note 123.

${ }^{143}$ See Roger L. Jansson, Research Liability for Negligence in Human Subject Research: Informed Consent and Researcher Malpractice Actions, 78 WASH. L. REV. 229, 230 (2003) ("[F]ew cases have generated reported decisions; thus the case law interpreting tort liability of researchers is scarce."); Michael Traynor, Clinical Trials: Emerging Products Liability And Insurance Issues, SB 16 ALI-ABA 179, 181 (1996) ("So far, there are very few reported cases involving liability for injury or death in clinical trials.").

${ }_{144}^{14}$ See, e.g., Traynor, supra note 143.

${ }^{145}$ Estimates suggest that ninety percent of cases involving potential research liability are dropped or settled, a figure comparable to the rate of medical malpractice suits that are dropped or settled. E. Haavi Morreim, Clinical Trials Litigation: Practical Realities as Seen from the Trenches, 12 ACCOUNTABILITy Res. 47, 52 (2005).

${ }^{146}$ In cases for which no informed consent was obtained, individuals have successfully sued for battery, an intentional tort that gives rise to punitive damages. See, e.g., Morreim, supra note 17, at 478 (noting that battery "requires no expert testimony, no finding that the procedure was performed negligently, and no causal connection between the battery and the injuries."). In some instances, the failure to obtain informed consent was deemed sufficient to be considered a constitutional violation. See Heinrich v. Sweet, 62 F. Supp. 2d 282, 313-15 (D. Mass. 1999) ("Failure to provide adequate disclosure of a potentially deadly medical experiment to subjects who were induced to participate on the basis of fraud constitutes a procedural irregularity sufficient to trigger the protections of the Fifth Amendment."); Stadt v. Univ. of Rochester, 921 F. Supp. 1023, 1027-28 (W.D.N.Y. 1996) ("The Constitution, and more specifically, the Due Process Clause of the Fifth Amendment clearly established a right to be free from non-consensual, governmental experimentation on one's body...."); In re Cincinnati Radiation Litig., 874 F. Supp. 796 (S.D. Ohio 1995) (finding a constitutional violation where plaintiffs were not informed that the radiation they were receiving was part of a military experiment rather than treatment of their cancer); $c f$. Bibeau v. Pac. Nw. Research 
expected, these cases are exceedingly rare. ${ }^{147}$ Instead, most cases brought for research-related injuries allege negligence. ${ }^{148}$

Injured research participants face several difficulties when seeking to recover under a tort law negligence regime. The first difficulty that injured research participants face is showing that researchers breached a duty owed to them. ${ }^{149}$ Unlike physicians who act primarily for the benefit of their patient, researchers are primarily loyal to the research protocol and the generalizable knowledge that benefits future patients. ${ }^{150}$ While doctors may be liable if they deviate from the generally accepted standard of care, research is an assessment of the effectiveness of those deviations from the standard of care. ${ }^{151}$

In recent years, both courts ${ }^{152}$ and scholars ${ }^{153}$ have seemingly settled on a duty of care owed that is satisfied when researchers comply with federal regulations.

Found., Inc., 188 F.3d 1105, 1112 n.6 (9th Cir. 1999) (finding that there was no constitutional violation of the right to bodily integrity because the litigants knew they were serving as experimental subjects rather than receiving treatment); Wright v. Fred Hutchinson Cancer Research Ctr., $269 \mathrm{~F}$. Supp. 2d 1286, 1295 (W.D. Wash. 2002) ("[I]n the absence of allegations that defendants hid the true nature of the experiments and/or conducted them for non-therapeutic reasons, there is no constitutional claim.").

${ }_{147}^{14}$ See, e.g., Morreim, supra note 17 , at 478.

${ }^{148}$ See, e.g., THE LEWIN GRP., supra note 129, at 39 ("Over time, negligence theory has replaced common law battery as the basis for malpractice litigation except in those cases in which no consent at all was obtained."). Injured research participants have brought suit alleging a wide variety of claims, including negligent and intentional infliction of emotional distress, fraud, breach of confidentiality, breach of contract, breach of privacy, product liability, and negligent conduct and monitoring of research. See, e.g., Michelle M. Mello et al., The Rise of Litigation in Human Subjects Research, 139 ANNALS INTERNAL MED. 40 (2003); THE LEWIN GRP., supra note 129, at 40. Claims have expanded to include alleged violations of rights based on the Nuremberg Code, the Declaration of Helsinki, the U.S. Constitution, or the federal civil rights acts, though courts have generally been reluctant to expand the rights in this way. See, e.g., Robertson ex rel. Robertson v. McGee, No. 01-CV-60-C, 2002 WL 535045 (N.D. Okla. Jan. 28, 2002); Heinrich ex rel. Heinrich v. Sweet, 49 F. Supp. $2 d 27$ (D. Mass. 1999); White v. Paulsen, 997 F. Supp. 1380 (E.D. Wash. 1998), But see Grimes v. Kennedy Krieger Inst., Inc., 782 A.2d 807, 835 (Md. 2001) (suggesting that a duty of care might arise from principles stated in the Nuremberg Code).

${ }^{149}$ See, e.g., Childress, supra note 32 , at 21 ("[M]alpractice suits depend on a standard duty of "due care' which may be unclear in research settings."). One major research liability case, Grimes $v$. Kennedy Krieger, went so far as to suggest that the duty owed by researchers to research participants should be determined on a case-by-base basis. Grimes, 782 A.2d at 858 . Grimes, however, has come under considerable scrutiny and has faced significant criticism. See, e.g., Diane E. Hoffman \& Karen H. Rothenberg, Whose Duty Is It Anyway?: The Kennedy Krieger Opinion and Its Implications for Public Health Research, 6 J. HEALTH CARE L. \& POL'Y 109 (2002). For an argument that the duties of physician-researchers should not be different from the duties owed by physicians providing clinical care, see Kathleen Cranley Glass \& Duff Waring, The Physician/Investigator's Obligation to Patients Participating in Research: The Case of Placebo Controlled Trials, 33 J.L. MED. \& ETHICS 575 (2005).

${ }^{150}$ Morreim, supra note 17, at 477 (noting that a researcher's "goal is not the betterment of any particular participant").

${ }^{151}$ See $i d$. ("The standard of care for medical practice emphasizes conformity to customary and prevailing practices.... In contrast, research cannot be judged by its conformity to customary practice since it is, by definition, an express deviation from those routines, taken to gather generalizable knowledge.") (internal citations omitted). While courts once held that a physician experimented "at his peril" if his patients were harmed thereby, see PUB. HEALTH SERV., supra note 76, at 25; Morreim, supra note 17 , at 476 , courts have increasingly recognized that medical progress requires experimentation, within permissible limits. See, e.g., Fortner v. Koch, 261 N.W. 762, 765 (Mich. 1935).

${ }^{152}$ See, e.g., Daum v. SpineCare Med. Grp., 61 Cal. Rptr. 2d 260 (Cal. Ct. App. 1997) (holding that the federal regulations designed to protect human research participants provided the standard of care); Whitlock v. Duke Univ., 637 F. Supp. 1463 (M.D.N.C. 1986) (holding that the Common Rule established the standard of care for an informed consent claim against researchers), 
Thus, researchers who have obtained informed consent, obtained IRB approval prior to beginning research, and satisfied a few additional legal requirements have seemingly satisfied their duties to research participants. But if compliance with the federal regulations satisfies the duty of care, only the very small class of participants injured while participating in non-compliant research will ever be able to bring suit successfully. ${ }^{154}$

Injured research participants also often have difficulty showing that the research intervention caused their injury. Participants who have a condition that causes symptoms similar to those resulting from the experimental treatment may have difficulty showing that it was the treatment, rather than the underlying condition, that caused injury. ${ }^{155}$ Participants may also have difficulty proving causation when an intervention creates a statistically higher chance of contracting disease at a later date. For example, tests of radiation exposure conducted by the U.S. government left participants with an increased chance of developing cancer. ${ }^{156}$ Exposed research participants who later contracted cancer could have difficulty proving that their particular cancer was more likely than not caused by the research intervention rather than some other circumstance. ${ }^{157}$ Injured research participants unable to prove causation to the satisfaction of the inflexible "more likely than not" legal standard will be denied recovery under the tort system. ${ }^{158}$

A third difficulty for injured research participants is the signed informed consent document. Before enrolling in research, participants are required by law to read and sign an informed consent document that lists all known risks of participation. ${ }^{159}$ The informed consent process is supposed to be thorough, with time spent ensuring that research participants understand the risks that they accept by participating in research. ${ }^{160}$ Jurisdictions that limit or preclude recovery under the assumption of risk doctrine would preclude research participants from recovering if

aff'd, 829 F.2d 1340 (4th Cir. 1987); Vodopest v. MacGregor, 913 P.2d 779 (Wash. 1996) (adopting the Common Rule as the standard of care for informed consent claims).

${ }^{153}$ See, e.g., Roger L. Jansson, Research Liability for Negligence in Human Subject Research: Informed Consent and Researcher Malpractice Actions, 78 WASH. L. REV. 229, 247 (2003) ("[T]here appears to be an emerging trend among courts to use the federal regulations as the standard of care for informed consent in human subject research."); Morreim, supra note 17, at 477 .

${ }^{154}$ See, e.g., Ferguson, supra note 41 , at 43 (noting that healthy British volunteers injured in infamous trials of TGN1412 could have trouble succeeding in a negligence lawsuit if the sponsors complied with research regulations).

${ }^{155}$ See, e.g., Resnik, supra note 89 , at 266 ("[I]t may be difficult to determine whether an injury was caused by a research study, the subject's underlying illness, the subject's failure to follow instructions, or some other cause."). ch. 17.

${ }^{156}$ See, e.g., AdVISORY COMm. ON HuMAN RADIATION EXPERIMENTS, supra note 46 , $\S$ III,

${ }^{157}$ See, e.g., Melissa Moore Thompson, Comment, Causal Inference in Epidemiology: Implications for Toxic Tort Litigation, 71 N.C. L. REV. 247, 280-82 (1992) (noting that with epidemiological calculations "population-based calculations should not be extrapolated directly to the individual").

${ }^{158}$ See, e.g., PrEsidenT's COMM'N, supra note 43, at 96 ("This often complex and scientifically demanding task typically must be performed to the satisfaction of a lay jury ...."). That is not to say that injured research participants should be able to forego proving causation. In fact, the proposal set forth in Part V.C requires that an injured research participant show, on balance of the probabilities, that the research caused the participant's injury. One key difference is that under the proposal, the causation element is evaluated by doctors and scientists most knowledgeable about the research intervention and the underlying disease rather than judges or juries.

${ }_{160}^{159}$ General Requirements for Informed Consent, 45 C.F.R. \& 46.116 (2005).

${ }^{160} \mathrm{Id}$. 
the researchers disclosed the potential injury in the informed consent document. ${ }^{161}$ Though intended to provide additional protection to research participants, a signed informed consent document could nevertheless create a legal barrier to recovery. ${ }^{162}$

The final, and perhaps most significant, difficulty is the tort system's requirement that the researcher be at fault. Routine research procedures-blood draws, biopsies, radiologic scans, and lumbar punctures-all carry a degree of risk, even when done properly. As noted by the Institute of Medicine, "[r]esearch cannot be entirely free of risk. Some research participants may incur a research-related injury even if the study is carried out without negligence and in full conformity with the protocol." 163 In the FIAU research discussed in the Introduction, individuals died as a result of their participation in research, yet an independent panel cleared the researchers of any negligence or wrong-doing. In the absence of strict liability, which has not been applied to biomedical research, ${ }^{164}$ injury without fault generally cannot result in compensation under a standard tort regime.

Under the current negligence approach, only an extremely limited subset of injured research participants can bring a successful tort lawsuit: those who were injured in research that did not comply with federal regulations, when the injury arose due to the researcher's fault, and in jurisdictions where research participants are not precluded from recovering by a signed informed consent document. ${ }^{165}$ As discussed in the next Part, this subset is limited even further by laws that deny whole classes of injured research participants access to the justice system.

\section{Several Classes of Research Participants Are Systematically UNCOMPENSATED}

In addition to the tort system posing challenges unique to all research participants that make recovering for research-related injuries exceedingly difficult, recent legal developments and a patchwork of legal doctrines prevent certain classes

${ }^{161}$ See, e.g., Slater v. Optical Radiation Corp., 961 F.2d 1330, 1334 (7th Cir. 1992) ("Provided the risks, including any loss of tort remedies, were adequately explained ... [,] he cannot complain that the risks materialized."); Schneider v. Revici, 817 F.2d 987, 996 (2d Cir. 1987) (signing an informed consent form for unorthodox cancer treatment created a jury question regarding patient's assumption of risk); PrEsidenT's COMM'N, supra note 43, at 86 ("An injured subject may also be required to overcome the claim that he or she assumed the risk of injury in agreeing to participate in the research."); Carl H. Coleman, Duties to Subjects in Clinical Research, 58 VAND. L. REV. 387, 410-11 n.98 (2005) ("Arguably, if a subject's explicit agreement to accept the inherent risks of research can be established, whether through the consent form or otherwise, the analytical framework would shift from primary implied assumption of risk to express assumption of risk . . .."); E. Haavi Morreim, Consumer-Defined Health Plans: Emerging Challenges from Tort and Contract, 39 J. HEALTH L. 307, 311 (2006) ("[I]nformed consent conversations will likely evolve.... [D]octrines like assumption of risk and contributory negligence/comparative fault can provide considerable insulation from tort claims ...."). But see Grimes v. Kennedy Krieger Inst., Inc., 782 A.2d 807, 835 (Md. 2001) ("Researchers cannot ever be permitted to completely immunize themselves by reliance on consents . ...."); Childress, supra note 32, at 25 (noting that assumption of risk requires that an individual know and understand the risk being incurred, an obligation arguably not satisfied in some research).

${ }^{162}$ See sources cited supra note 161.

${ }^{163}$ INST. OF MED., supra note 72, at 188.

164 Strict liability for research-related injuries has been considered, but rejected. See, e.g., SECRETARY'S TASK FORCE, supra note 77, at V-3 ("While the concept of strict liability has been expanded in recent years, ... [t] here is no indication that the courts are prepared to impose such strict liability upon the research community."); PRESIDENT's COMM'N, supra note 43, at 94 ("[T]he proposition that research with human subjects is an 'abnormally dangerous activity' subject to strict liability standards finds no clear support in the empirical evidence or in legal precedent.").

${ }^{165}$ PRESIDENT's COMM'N, supra note 43, at 83-84. 
of research participants-participants in federally conducted research ${ }^{166}$ and international participants-from recovering through the tort system. This patchwork of legal doctrines results in classes of injured research participants being denied compensation in tort based on distinctions that are ethically irrelevant. U.S. participants injured as a result of participating in privately conducted research have difficulty recovering due to the principles set forth above but face no additional legal obstacles and so are not discussed below.

\section{U.S. Participants in Federally Conducted Research}

Various legal doctrines-sovereign immunity, the Federal Tort Claims Act (FTCA), and the discretionary function exception-protect the government from liability arising from most federally conducted research. ${ }^{167}$ As applied, participants injured as a result of participating in federally conducted research can only successfully sue the federal government to the extent that their injuries arise from actions that violate statutory and regulatory requirements. ${ }^{168}$

The federal government is generally immune from suit under the doctrine of sovereign immunity. ${ }^{169}$ Except in the limited circumstances in which the government consents to be sued, individuals - including injured research participants-are unable to bring suit against the federal government for injuries arising out of acts by federal government employees. ${ }^{170}$

One statute by which the government has consented to be sued is the FTCA, a law that waives governmental immunity for injuries arising from torts committed by government employees to the extent that private individuals would be liable for similar injuries under state tort law. ${ }^{171}$ Under the FTCA, the federal government can

${ }^{166}$ This category is limited primarily to federally conducted research, and does not include all federally funded research. See SECRETARY'S TASK FORCE, supra note 77, at V-1 (exploring "[f]ederally conducted, supported (by grant or contract), and regulated research, particularly research covered by the Federal Food, Drug, and Cosmetic Act"). Private entities receiving federal funds to conduct research will be treated as non-federal entities, except to the extent they are so closely supervised to be considered deputized federal agents. See, e.g., Heinrich ex rel. Heinrich v. Sweet, 62 F. Supp. 2d 282 (D. Mass. 1999) (finding that Associated Universities-a private corporation founded by Harvard, Yale, and a number of other universities to operate research laboratories-could be considered governmental for purposes of immunity due to the supervision and control exercised by the government).

${ }^{167}$ See, e.g., Andrew Hyer, The Discretionary Function Exception to the Federal Tort Claims Act: A Proposal for a Workable Analysis, 2007 BYU L. REV. 1091, 1094-95 (2007) (discussing governmental protection from liability under the discretionary function exception); Mark C. Niles, "Nothing but Mischief": The Federal Tort Claims Act and the Scope of Discretionary Immunity, 54 ADMIN. L. REV, 1275, 1279-80 (2002) (arguing that the FTCA, though meant to extend liability in cases of federal employees and officers committing torts, has not been applied as such); infra note 169 and accompanying text.

${ }^{168}$ See Niles, supra note 167 , at 1292 (noting that courts hear cases in which the government has violated a "regulation, statute, or Constitutional provision").

${ }^{169}$ See, e.g., Hercules, Inc. v. United States, 516 U.S. 417, 417 (1996) "The United States, as sovereign, is immune from suit save as it consents to be sued and the terms of its consent to be sued in any court define that court's jurisdiction to entertain the suit.") (internal citations omitted); FDIC v. Meyer, 510 U.S. 471, 471 (1994) ("Absent a waiver, sovereign immunity shields the Federal Government and its agencies from suit."); Federal Hous. Admin. v. Burr, 309 U.S. 242, 244 (1940) ("[T]he United States cannot be sued without its consent.").

${ }^{170}$ See cases cited supra note 169.

${ }^{171}$ See Liability of United States, 28 U.S.C. $\$ 1346(b)(1)(2010)$. An exception to Sovereign Immunity that will not be discussed in detail in this Article is the Tucker Act, which waives governmental immunity when the government enters into a contract. See Claims against United States generally, 28 U.S.C. $\S 1491$ (2011). An injured research participant might pursue a claim under the Tucker Act on the theory that the informed consent document creates a contract, the terms of which 
be liable for research-related injuries to the same extent private sponsors of research would be liable. ${ }^{172}$

But the discretionary function exception to the FTCA renders the United States immune from suit for discretionary acts even though a private individual could be held liable. ${ }^{173}$ The purpose of the exception is to prevent judicial second-guessing of discretionary decisions that should rightfully be made by those hired to make them. ${ }^{174}$ The Supreme Court has interpreted the discretionary function exemption broadly, ${ }^{175}$ rendering a wide variety of acts by the federal government immunized under the discretionary function exception, ${ }^{176}$ including acts related to research. ${ }^{177}$

Courts have held the discretionary function exception to immunize the federal government from liability arising from the planning and execution of research. Two courts of appeals held that the discretionary function exception applied to atomic testing research conducted by the federal government, during which civilians were systematically exposed to atomic energy to measure its effects. ${ }^{178}$ Those injured brought suit alleging that the government could have and should have done more to protect the research participants. ${ }^{179}$ The U.S. Court of Appeals for the Ninth Circuit noted that the research program "required difficult judgments balancing the magnitude of the risk from radiation exposure ... against the risks and burdens of a

bind the U.S. government. Though there is some support for the "informed consent as contract" argument, see, e.g., Dahl v. Hem Pharm. Corp., 7 F.3d 1399 (9th Cir. 1993) (holding that a consent form in a research protocol formed a unilateral contract); Grimes v. Kennedy Kriger Inst., Inc., 782 A.2d 807, 843 (Md. 2001) (noting that an informed consent document can create a contract); Lori A. Alvino, Note, Who's Watching the Watchdogs? Responding to the Erosion of Research Ethics by Enforcing Promises, 103 CoLUM. L. REV. 893, 919-20 (2003), the Tucker Act explicitly excludes cases that sound in tort, see 28 U.S.C. $\$ 1491$ (a)(1). Given that the underlying claim could sound in tort, an action may be precluded by statutory language. To the extent the informed consent document governs, any injury that is disclosed in the informed consent document could preclude recovery.

${ }^{172}$ See Niles, infra note 167 , at 1279 "'The FTCA is a revolutionary statute which purports to 'waive' the sovereign immunity of the United States in cases arising out of torts committed by its employees and officers.").

${ }^{173}$ See Exceptions, 28 U.S.C. $\$ 2680$ (a) (2010). Once governmental actions have been labeled discretionary, it is immaterial whether or not actions are performed negligently. 14 CHARLES ALAN WRIGHT ET AL., FEDERAL PRACTICE AND PROCEDURE $\$ 3658.1$ (3d ed. Supp. 2011 ).

${ }^{174}$ See, e.g., Berkovitz v. United States, 486 U.S. 531, 538 (1988) (according this analysis "with Congress's purpose in enacting the exception: to prevent 'judicial intervention in . . the political, social, and economic judgments' of governmental ... agencies" (quoting United States v. Varig Airlines, 467 U.S. 797, 820 (1984))).

${ }^{175}$ See, e.g., Hyer, supra note 167 , at 1108 ("[M]any contend that the Supreme Court's current approach unfairly leaves an injured party without a remedy simply because the injury was caused by a government actor...."); Niles, supra note 167, 1279 ("[The FTCA] had been interpreted by the United States Supreme Court to allow for a restriction on federal tort liability that is ... essentially identical to that applicable before the law was passed.").

${ }^{176}$ See, e.g., Merando v. United States, 517 F.3d 160 (3d Cir. 2008) (holding that the discretionary-function exception applies to the National Forest Service's decision not to cut down dead trees); Childers v. United States, 40 F.3d 973 (9th Cir. 1994) (holding that the decision of the National Park Service not to post warnings or close a trail was discretionary); In re "Agent Orange" Prod. Liab. Litig., 818 F.2d 210 (2d Cir. 1987) (holding that the government's decision to use Agent Orange as a defoliant was discretionary); Ramirez v. U.S. Postal Serv., 893 F. Supp. 121 (D.P.R. 1995) (holding that implementation of security measures for a post office is discretionary).

${ }_{177}$ See, e.g., Bibeau v. Pac. Nw. Research Found., Inc., 339 F.3d 942 (9th Cir. 2003) (holding that the United States's decision not to supervise government-funded research experiments testing the effects of radiation on human testicular function was discretionary); Hagy v. United States, 976 F. Supp. 1373 (W.D. Wash. 1997) (holding that the government's decision to delegate safety and warning responsibilities to independent medical researchers was discretionary).

${ }^{178}$ E.g., In re Consol. U.S. Atmospheric Testing Litig., 820 F.2d 982 (9th Cir. 1987); Allen v. United States, 816 F.2d 1417 (10th Cir. 1987).

${ }^{179}$ See cases cited supra note 177. 
public program," 180 and that "every aspect of a warning program is a matter that falls within the discretionary function exception." ${ }^{\prime 181}$ Faced with similar facts, the U.S. Court of Appeals for the Tenth Circuit noted that "[p]laintiffs' entire case rests on the fact that the government could have made better plans. That is probably correct, but is insufficient for FTCA liability."182

Injured research participants cannot bring suit for injuries arising from any part of research that is discretionary-a term of art interpreted broadly. ${ }^{183}$ This leaves open the possibility of recovery from the federal government only for injuries arising from research acts that are not discretionary, i.e., violations of statutes, regulations, or mandatory policies. ${ }^{184}$ Because research is highly regulated such that most federally conducted research is compliant with the regulations, most aspects of research giving rise to injury will be immunized by the discretionary function exception. ${ }^{185}$ Participants injured as a result of participating in federally conducted research are not likely to be able to recover for their injuries through the tort system.

\section{International Participants in Federally Conducted Research}

International participants injured as a result of participating in federally conducted research are entitled to even less protection. As discussed above, the U.S. government is generally immune from suit under principles of sovereign immunity, unless an exception applies. ${ }^{186}$ The exception applicable to federally conducted research-the FTCA-does not apply to acts that occur abroad. ${ }^{187}$ Nor does the Alien Tort Statute (ATS), a statute that grants jurisdiction to U.S. courts to hear cases of torts committed abroad in violation of the law of nations, waive sovereign immunity. ${ }^{188}$ Accordingly, international research participants who are injured as a result of participating in federally conducted research are unable to access the U.S. justice system.

The extent of governmental immunity from tort liability arising from federally conducted research abroad is now being tested. In 2010, Professor Susan Reverby uncovered evidence that between 1946 and 1948, U.S. researchers deliberately infected prisoners and mental health patients in Guatemala with disease. ${ }^{189}$ Upon learning of the research, Guatemala expressed outrage that such research was permitted and threatened to bring suit in U.S. courts. ${ }^{190}$ Lawyers representing the

${ }^{180}$ In re Consol. U.S. Atmospheric Testing Litig., 820 F.2d at 997.

${ }^{181}$ Id. at 998.

${ }^{182}$ Allen, 816 F.2d at 1424.

${ }^{183}$ See supra notes $175-77$ and accompanying text.

${ }^{184}$ See, e.g., Heinrich ex rel. Heinrich v. Sweet, 62 F. Supp. 2d 282, 323 (D. Mass. 1999) (internal citations omitted) ("An act is not discretionary if a federal statute, regulation, or policy mandates a course of action for an employee to follow ....."). Even negligently conducted research may not give rise to liability if the original act was discretionary because once governmental actions have been labeled discretionary, it is immaterial whether those actions have been performed negligently-the government is immune from suit. WRIGHT ET AL., supra note 173, $\$ 3658.1$.

${ }_{185}^{185}$ See, e.g., WRIGHT ET AL., supra note 173; sources cited supra note 175.

${ }^{186}$ See supra notes $167-68$ and accompanying text.

${ }^{187}$ See Exceptions, 28 U.S.C. $\S 2680(\mathrm{k})(2005)$. The foreign country exception was interpreted broadly in the Supreme Court's recent decision Sosa v. Alvarez-Machain, 542 U.S. 692 (2004).

${ }_{188}$ See, e.g., Industria Panificadora, S.A. v. United States, 957 F.2d 886, 887 (D.C. Cir. 1992) (dismissing on sovereign immunity grounds the ATS claims against the United States); Goldstar (Panama), S.A. v. United States, 967 F.2d 965, 967-69 (4th Cir. 1992) (same); Canadian Transp. Co. v. United States, 663 F.2d 1081, 1091-92 (D.C. Cir. 1980) (same).

${ }^{189}$ Reverby, supra note 10.

${ }^{190}$ See id. at 22 (noting the worldwide outrage sparked upon learning of the Guatemala study). 
victims asked the United States to establish an out-of-court settlement procedure similar to those established for the Gulf of Mexico oil spill or, alternatively, to waive sovereign immunity. ${ }^{191}$ When these demands were not met, a class-action lawsuit was filed, ${ }^{192}$ and the federal government responded with a motion to dismiss on grounds of sovereign immunity. ${ }^{193}$ The families of the research participants may soon learn precisely how limited the remedies are for injured international research participants.

\section{International Participants in Privately Conducted Research}

The tort system prevents international research participants who are injured as a result of participating in privately conducted research from recovering due to entirely different substantive and procedural barriers. ${ }^{194}$ As set forth below, recent legal decisions by the U.S. Court of Appeals for the Second Circuit have foreclosed recovery under the ATS, which is the primary way foreign individuals injured abroad brought suit in the United States. ${ }^{95}$ International research participants also are often blocked procedurally by forum non conveniens, a doctrine that permits courts to dismiss cases to more suitable forums abroad. ${ }^{196}$ Together these operate to deny injured international research participants access to the U.S. justice system in the event of a research-related injury.

\section{a. Substantive Barriers to Recovery: Corporate Liability Under the Alien Tort Statute}

In 1996, Nigeria was suffering through an outbreak of bacterial meningitis. ${ }^{197}$ At the time of the outbreak, Pfizer was near FDA approval of its presumed wonder drug Trovan, and having collected data on safety and efficacy in adults, decided to conduct its remaining research in Nigeria. ${ }^{198}$ Allegedly working in concert with Nigerian doctors and Nigerian government officials, Pfizer recruited 200 sick children who sought treatment at the local hospital. ${ }^{199}$ Half of the children were given Trovan, Pfizer's experimental drug, and the other half were given Ceftriaxone, an FDA-approved drug, the safety and efficacy of which had already been established. ${ }^{200}$

Pfizer allegedly knew that Trovan had never previously been tested on children in the form that was used, and that animal tests had shown life-threatening side effects that included joint disease, abnormal cartilage growth, liver damage, and a degenerative bone condition. ${ }^{201}$ In conducting its research, Pfizer allegedly gave the

191 U.S. Sued Over Syphilis Tests in Guatemala, CBC NEws (Mar. 14, 2011, 1:22 PM), http://www.cbc.ca/news/health/story/2011/03/14/syphilis-guatemala-obama-lawsuit.html.

${ }^{192}$ Class Action Complaint for Injunctive Relief and Damages, Garcia v. Sebelius, No. 1:11-cv00527-RBW (D.D.C. Mar. 14, 2011).

${ }^{193}$ E.g., Nedra Pickler, US Argues It Is Immune from STD Experiment Lawsuit, AsSOCIATED PRESS, Jan. 9, 2012, available at http:/www.boston.com/yourtown/wellesley/articles/2012/01/ 10/us argues_it_is_immune_from_std_experiment_lawsuit/.

${ }^{\overline{194}}$ See discussion infra Part IIII.C.3.

${ }^{195}$ For more information about the ATS, see infra Part III.C.3.a

${ }^{196}$ For more information about forum non conveniens, see infra Part III.C.3.b.

${ }^{197}$ See Abdullahi v. Pfizer, Inc., 567 F.3d 163, 169 (2d Cir. 2009), cert denied, 130 S. Ct. 3541 (2010).

${ }^{198}$ See id.
${ }^{199} \mathrm{Id}$.
${ }^{200} \mathrm{Id}$.
${ }^{201} \mathrm{Id}$.


control group a deliberately low dose of the control drug Ceftriaxone to misrepresent the effectiveness of Trovan. ${ }^{202}$ After two weeks of research, Pfizer allegedly left without administering follow-up care. ${ }^{203}$ Of those who participated in the research, eleven children died and many others were left blind, deaf, paralyzed, or brain damaged. ${ }^{204}$ It is difficult to determine with certainty the extent to which these injuries were a result of exposure to the experimental drug or a consequence of under-treating the bacterial meningitis. ${ }^{205}$

Following a Washington Post exposé that highlighted the nature of Pfizer's research, ${ }^{206}$ injured research participants brought suit alleging that Pfizer failed to obtain any informed consent from research participants, failed to disclose or explain the experimental nature of the study or the serious risks involved, failed to alert children or their guardians of the side effects of Trovan, and failed to inform participants that Doctors Without Borders was providing conventional, effective treatment free of charge at the same site. ${ }^{207}$

The families sought compensation under the ATS, which gives district courts original jurisdiction over any civil action brought "by an alien for a tort only, committed in violation of the law of nations." ${ }^{208}$ Though enacted in 1789 , the Supreme Court did not address the scope of liability under the ATS until the 2004 decision Sosa v. Alvarez-Machain, ${ }^{209}$ in which the Supreme Court held that only a "narrow set of violations of the law of nations, admitting of judicial remedy and at the same time threatening serious consequences in international affairs," would be actionable under the ATS. ${ }^{210}$ The issue before the Second Circuit was whether nonconsensual medical research rose to the level of a violation of the law of nations. ${ }^{211}$

Under Second Circuit precedent, only norms sufficiently universal, specific, and mutual, i.e., norms with cross-border implications, were held to rise to the level of the law of nations. ${ }^{212}$ The Abdullahi court concluded that the norm against nonconsensual medical experimentation was sufficiently universal, ${ }^{213}$ specific, ${ }^{214}$ and mutual ${ }^{215}$ to rise to that level. ${ }^{216}$ In what would come to serve as the high-water mark

${ }^{202} \mathrm{Id}$.
${ }^{203} \mathrm{Id}$.
${ }^{204} \mathrm{Id}$.
${ }^{205}$ Purportedly some of the subjects were deliberately given a reduced dose of Ceftriaxone, so their deaths were likely a result of the underlying disease and could have been avoided with a proper dose of the drug. See id.

${ }^{206}$ See Stephens, supra note 6, at A01.

${ }^{207}$ Abdullahi, 562 F.3d at 170.

${ }^{208}$ See Alien's Action for Tort, 28 U.S.C. $\$ 1350$ (2006).

${ }^{209}$ Sosa v. Alvarez-Machain, 542 U.S. 692 (2004); see also Abdullahi, 562 F.3d at 173.

${ }^{210}$ Sosa, 542 U.S. at 715.

${ }^{211}$ Abdullahi, 562 F.3d at 172-74.

${ }^{212} \mathrm{Id}$. at 174 .

${ }^{213} \mathrm{Id}$. at 180-82 (finding sufficient universality because the principle had been embedded in U.S. law by Congress, had been embedded in the laws of eighty-four other countries, and had been articulated in a number of international treaties).

${ }^{214} \mathrm{Id}$. at 184 (concluding that a "norm forbidding nonconsensual human medical experimentation is every bit as concrete-indeed even more so-than the norm prohibiting piracy . . . or interference with the right of safe conducts and the rights of ambassadors ...").

${ }^{215} \mathrm{Id}$. at 186 (finding sufficient mutuality because the administration of unethical biomedical research had potential for cross-border implications that threatened international peace and security). The Trovan trials apparently engendered distrust among the local population and contributed to an eleven-month-long boycott of a polio vaccination campaign in 2004, which impeded international and national efforts to vaccinate the population. As a result, between 2003 and 2006, a polio outbreak that originated in Nigeria triggered a major international outbreak, causing polio to spread and to re-infect twenty previously polio-free countries. $I d$. This possibility for global catastrophes, as well as the 
for injured international research participants, Pfizer ultimately settled its suit with the $A$ bdullahi plaintiffs for a reported seventy-five million dollars. ${ }^{217}$

The glimmer of hope provided to injured international research participants by the Abdullahi decision was short-lived. Little more than a year after the Second Circuit decided Abdullahi, the court seemingly reversed course in addressing the more general question of corporate liability under the ATS. In Kiobel v. Royal Dutch Petroleum, ${ }^{218}$ the Second Circuit held that "insofar as plaintiffs bring claims under the ATS against corporations, plaintiffs fail to allege violations of the law of nations, and plaintiffs' claims fall outside the limited jurisdiction provided by the ATS." The court squared its decision with Abdullahi by saying that the Abdullahi court had assumed, without deciding, that corporations could be held liable under the ATS. ${ }^{220}$

The Second Circuit reached its conclusion that corporations could not be liable under the ATS by looking to the treatment of corporations both historically and under international law. ${ }^{221}$ The court found insufficient evidence that corporations had been held liable historically or are held liable currently for violations of international law. ${ }^{222}$ An impassioned dissent disagreed, pointing to early interpretations of the ATS that suggested that corporations could be held liable ${ }^{223}$ and noting that corporations in other countries are routinely held civilly liable for violations of international law. 224

possibility of unethical research generating substantial anti-American animus and hostility, led the court to the conclusion that the norm was sufficiently mutual. Id. at 187 .

${ }^{216}$ Although the holding in $A b d u l l a h i$ has been challenged as imprudently racing to declare a new form of international law, the right to be free from non-consensual experimentation on one's body has been recognized throughout U.S. history. See, e.g., Albright v. Oliver, 510 U.S. 266, 272 (1994) (internal citation omitted) (finding that "the protections of substantive due process have for the most part been accorded to matters relating to marriage, family, procreation, and the right to bodily integrity"); Schmerber v. California, 384 U.S. 757, 772 (1966) ("The integrity of an individual's person is a cherished value of our society ....."); Union Pac. R.R. v. Botsford, 141 U.S. 250, 251 (1891) (finding that "no right is held more sacred, or is more carefully guarded, by the common law, than the right of every individual to the possession and control of his own person, free from all restraint or interference of others...").

${ }^{217}$ See Joe Stephens, Pfizer to Pay $\$ 75$ Million to Settle Nigerian Trovan-Testing Suit, WASH. PosT, July 31, 2009, at A 15 .

${ }^{218}$ Kiobel v. Royal Dutch Petroleum Co., 621 F.3d 111 (2d Cir. 2010).

${ }^{219} \mathrm{Id}$. at 120 . The court noted that suits "against the individual perpetrators of violations of customary international law-including the employees, managers, officers, and directors of the corporation" may still be brought under the ATS. Id. at 122.

${ }^{220}$ See id. at 124 ("We have, in the past, decided ATS cases involving corporations without addressing the issue of corporate liability.").

${ }_{221}$ See id. at 125-27.

${ }^{222}$ See id. at 145 .

${ }^{223}$ See id. at 162 (noting a 1907 U.S. Attorney General opinion that held that corporations could be liable under the ATS).

${ }^{224}$ See $i d$. at 152 ("[T]he imposition of civil liability on corporations serves perfectly the objective of civil liability to compensate victims for the wrongs inflicted on them and is practiced everywhere in the world."); see also Barnali Choudhury, Beyond the Alien Tort Claims Act: Alternative Approaches to Attributing Liability to Corporations for Extraterritorial Abuses, 26 NW. J. INT'L L. \& BUS. 43, 54-55 (2005) (noting that Canada, Australia, and England have held corporations liable for human rights violations committed abroad); Andrei Mamolea, The Future of Corporate Aiding and Abetting Liability Under the Alien Tort Statute: A Roadmap, 51 SANTA ClaRA L. REV. 79, 97 (2011) (noting that laws imposing criminal liability on corporations for violations of international law are widespread. Over half a dozen countries, including Australia, Canada, France, the Netherlands, Norway, and the UK, impose criminal liability on corporations for violations of international law.). The dissent pointed to policy reasons that would warrant holding corporations liable under the ATS. The ATS is an important tool to ensure the protection of fundamental human rights. Immunizing corporations from civil liability under the ATS could incentivize bad behavior. See Kiobel, 621 F.3d at 149-50. 
Prior to Kiobel, courts that had considered the issue of corporate liability under the ATS had overwhelmingly and explicitly concluded that corporations were subject to suit in the United States under the ATS. ${ }^{225}$ Only one case had ever been outright dismissed under the theory that corporations are not liable under the ATS. ${ }^{226}$ As a result of the Second Circuit's decision in Kiobel, a number of cases brought alleging corporate liability under the ATS have been summarily dismissed. ${ }^{27}$

As expected, ${ }^{228}$ the Supreme Court granted certiorari to hear Kiobel. ${ }^{229}$ The Court will have to reconcile two competing lines of cases: the first granting

${ }^{225}$ Cases permitting corporate liability under the ATS had been decided by the Court of Appeals for the Second Circuit. See, e.g., Presbyterian Church of Sudan v. Talisman Energy, Inc., 582 F.3d 244, 261 n.12 (2d Cir. 2009) ("We will also assume, without deciding, that corporations . . . may be held liable for the violations of customary international law that plaintiffs allege."); Khulumani $v$. Barclay Nat'l Bank Ltd., 504 F.3d 254, 282 (2d Cir. 2007) (Katzmann, J., concurring) ("[Courts have] repeatedly treated the issue of whether corporations may be held liable under the [ATS] as indistinguishable from the question of whether private individuals may be."); Wiwa v. Royal Dutch Petroleum Co., 226 F.3d 88 (2d Cir. 2000) (reversing the district court's dismissal of ATS complaint against corporations on forum non conveniens grounds); Jota v. Texaco, Inc., 157 F.3d 153, 155 (2d Cir. 1998) (vacating district court's dismissal of ATS case against corporation on forum non conveniens grounds).

District courts within the Second Circuit had repeatedly held that corporations could be liable under the ATS. See, e.g., In re S. Afr. Apartheid Litig., 617 F. Supp. 2d 228, 254 (S.D.N.Y. 2009) ("On at least nine separate occasions, the Second Circuit has addressed [ATS] cases against corporations without ever hinting-much less holding-that such cases are barred."); In re "Agent Orange" Prod. Liab. Litig., 373 F. Supp. 2d 7, 58 (E.D.N.Y. 2005) ("A corporation is not immune from civil legal action based on international law."); Presbyterian Church of Sudan v. Talisman Energy, Inc., 374 F. Supp. 2d 331, 335 (S.D.N.Y. 2005) ("Talisman's argument that corporate liability under international law is not ... sufficiently accepted in international law to support an ATS claim is misguided.").

Cases in both the Ninth and Eleventh Circuits concluded that corporations could be liable under the ATS. See, e.g., Sinaltrainal v. Coca-Cola Co., 578 F.3d 1252, 1263 (11th Cir. 2009) ("In addition to private individual liability, we have also recognized corporate defendants are subject to liability under the ATS and may be liable for violations of the law of nations."); Romero v. Drummond Co., 552 F.3d 1303, 1315 (11th Cir. 2008) ("The text of the Alien Tort Statute provides no express exception for corporations ... and the law of this Circuit is that this statute grants jurisdiction from complaints of torture against corporate defendants."); Sarei v. Rio Tinto, PLC, 487 F.3d 1193 (9th Cir. 2007), vacated in part on other grounds, 550 F.3d 822 (9th Cir. 2008) (en banc) (concluding that claims against an international mining corporation were sufficient to warrant exercise of federal jurisdiction under the ATS); Doe I v. Unocal Corp., 395 F.3d 932, 947 (9th Cir. 2002) (concluding that a corporation may be subject to suit under the ATS for aiding and abetting violations of customary international law), reh'g en banc granted, 395 F.3d 978 (9th Cir. 2003), appeal dismissed, 403 F.3d 708 (9th Cir. 2005).

District courts in several other circuits have concluded similarly. See, e.g., Al-Quraishi v. Nakhla, 728 F. Supp. 2d 702, 755 (D. Md. 2010) ("[T]here is broad judicial agreement that the ATS provides for corporate liability."); In re XE Servs. Alien Tort Litig., 665 F. Supp. 2d 569, 588 (E.D. Va. 2009) ("Nothing in the ATS or Sosa may plausibly be read to distinguish between private individuals and corporations; indeed, Sosa simply refers to both individuals and entities as "private actors." $)$.

${ }^{226}$ See Abagninin v. Amvac Chem. Corp., 545 F.3d 733, 741-42 (9th Cir. 2008).

${ }^{227}$ See, e.g., Mastafa v. Chevron Corp., 759 F. Supp. 2d 297, 300-01 (S.D.N.Y. 2010) (dismissing suit brought under the ATS stating that, under Kiobel, corporations cannot be liable under the ATS); see also Doe v. Nestle, 748 F. Supp. 2d 1057, 1116 (C.D. Cal. 2010) (dismissing an ATS action holding that customary international law does not apply to corporations).

${ }^{228}$ The Supreme Court expressed interest in deciding the issue of corporate liability under the ATS once Abdullahi v. Pfizer was decided, and invited the solicitor general to file a brief expressing the views of the United States. Pfizer v. Abdullahi, $130 \mathrm{~S}$. Ct. 534 (2010) (mem.) (inviting the solicitor general to file a brief expressing the views of the United States). The Supreme Court ultimately denied certiorari at the behest of the solicitor general. Abdullahi v. Pfizer, 562 F.3d 163 (2009), cert. denied, $130 \mathrm{~S}$. Ct. 3541 (2010); Brief for the United States as Amicus Curiae at 1 , Abdullahi, 562 F.3d 163 (No. 09-34). The Kiobel decision also creates a circuit split with regards to 
corporations the same rights and duties owed to individuals, ${ }^{230}$ which suggests that corporations will be liable under the ATS given that individual liability under the ATS is well-established; and the second minimizing the extraterritorial application of U.S. law, ${ }^{231}$ suggesting a more limited application of the ATS. ${ }^{232}$ Unless or until the Kiobel decision is overturned by the Supreme Court, it remains the law of the Second Circuit-the circuit with the most established ATS jurisprudence ${ }^{233}$ - and serves as an absolute barrier to recovery for international research participants injured as a result of participating in privately conducted research.

\section{b. Procedural Obstacle to Recovery: Forum Non Conveniens}

Aside from the substantive legal barriers to recovery posed by the Kiobel decision, injured international research participants face a procedural obstacle in the form of forum non conveniens. Forum non conveniens is a discretionary doctrine that permits a court to decline to hear a case on the basis that a more appropriate alternative forum exists elsewhere. ${ }^{234}$ Under the principle of forum non conveniens, courts may consider a variety of factors in determining whether another court is better situated to hear a case, including the location of where the injury occurred. ${ }^{235}$

corporate liability under the ATS, with recent decisions by the D.C. Circuit, the Seventh Circuit, the Ninth Circuit, and the Eleventh Circuit holding that corporations can be liable under the ATS. See Doe v. Exxon Mobil Corp., 654 F.3d 11, 57 (D.C. Cir. 2011) ("[I]t would create a bizarre anomaly to immunize corporations from liability for the conduct of their agents in lawsuits brought for 'shockingly egregious violations of universally recognized principles of international law.'" (quoting Zapata v. Quinn, 717 F.2d 691 (2d Cir. 1983))); Flomo v. Firestone Nat'1 Rubber Co., 643 F.3d 1013, 1017 (7th Cir. 2011) (holding that corporations can be liable under the ATS, and calling Kiobel an "outlier"); Sinaltrainal, 578 F.3d at 1263 ("In addition to private individual liability, we have also recognized corporate defendants are subject to liability under the ATS and may be liable for violations of the law of nations."); Romero, 552 F.3d at 1315 ("The text of the Alien Tort Statute provides no express exception for corporations ... and the law of this Circuit is that this statute grants jurisdiction from complaints of torture against corporate defendants."); Sarei, 487 F.3d at 1193.

${ }^{229}$ Kiobel v. Royal Dutch Petroleum Co., No. 10-1491, 2011 WL 4905479 (U.S. Oct. 17, 2011 ).

${ }^{230}$ See, e.g., Citizens United v. FEC, 130 S. Ct. 876 (2010) (holding that corporations are entitled to First Amendment protection for political speech). But see FCC v. AT\&T, Inc., $131 \mathrm{~S}$. Ct. 1177 (2011) (holding that corporations are not persons for purposes of the personal FOIA exemption).

${ }^{231}$ See, e.g., Morrison v. Nat'l Austl. Bank Ltd., 130 S. Ct. 2869 (2010) (limiting the extraterritorial application of the Securities Exchange Act of 1934); EEOC v. Arabian American Oil Co., 499 U.S. 244, 248 (1991) ("[L]egislation of Congress, unless a contrary intent appears, is meant to apply only within the territorial jurisdiction of the United States." (citing Foley Bros. v. Filardo, 336 U.S. 281, $285(1949))$ )

${ }^{232}$ For a thoughtful and fulsome argument that corporations should be held liable under the ATS, see, for example, Mamolea, supra note 224 . For an argument to the contrary, see Julian Ku, The Curious Case of Corporate Liability Under the Alien Tort Statute: A Flawed System of Judicial Lawmaking, 52 VA. J. INT'L L. 353 (2011).

${ }^{233}$ Theresa (Maxi) Adamski, The Alien Tort Claims Act and Corporate Liability: A Threat to the United States' International Relations, 34 FORDHAM INT'L L.J. 1502, 1522 (2011) (“[T]he Second Circuit ... has heard a substantial number of ATCA cases and, consequently, handed down a series of important decisions concerning corporate liability.").

${ }_{234}$ See, e.g., Jolyon Ford \& George Tomossy, Clinical Trials in Developing Countries: The Plaintiff's Challenge, L. SOC. JUST. \& GLOBAL DEV. J. 1 (2004), available at http://www2.warwick.ac.uk/fac/soc/law/elj/lgd/2004_l/ford/.

${ }^{235}$ Among the factors a court may consider in deciding whether to decline jurisdiction on the grounds of forum non conveniens, some of which might argue in favor of a foreign forum, are: the location of potential witnesses, the location of relevant evidence and records, possible undue hardship for the defendant, availability of adequate alternative forums for the plaintiff, the expeditious use of judicial resources, the choice of law applicable to the dispute, and the location where the cause of action arose. See, e.g., Piper Aircraft Co. v. Reyno, 454 U.S. 235 (1981). 
The $A b d u l l a h i$ plaintiffs provide a striking example of the way in which forum non conveniens can serve to delay or potentially deny access to U.S. courts. Abdullahi involved a clinical trial conducted by Pfizer in Kano, Nigeria, that resulted in the death of eleven children and serious injuries in scores of others. ${ }^{236}$ The Abdullahi plaintiffs first brought suit in the Southern District of New York, alleging that Pfizer's experiment violated international law. ${ }^{237}$ The case was dismissed in 2002 on grounds of forum non conveniens when the court found that Nigeria would be an adequate alternative forum. ${ }^{238}$

The Abdullahi plaintiffs encountered several obstacles in Nigeria. The first Nigerian judge was removed from the bench, a second judge declined to exercise jurisdiction for personal reasons, and the suit was ultimately dismissed without resolution. ${ }^{239}$ In 2007, the Nigerian state of Kano brought independent criminal charges and civil claims against Pfizer seeking over two billion dollars in damages and restitution, and the federal government of Nigeria brought suit against $P$ fizer and its employees seeking seven billion dollars in damages. ${ }^{240}$ Only when faced with the possibility of enormous civil and criminal liability in Nigeria did Pfizer agree to litigate in the United States. ${ }^{241}$

As illustrated by Abdullahi, in the event of dismissal under forum non conveniens, injured international research participants may be unable to obtain adequate remedies abroad. Hosting research brings additional medical jobs and healthcare to a community, and countries may worry that lawsuits against researchers will discourage future research. ${ }^{242}$ Accordingly, impoverished countries may actively discourage injured research participants from bringing lawsuits against sponsors. ${ }^{243}$ Additionally, companies may be judgment-proof in foreign jurisdictions, ${ }^{244}$ and countries may not have as established a civil tort law system as does the United States. ${ }^{245}$ These barriers to recovery are sufficient to deny international research participants injured as a result of participating in privately conducted research meaningful access to compensation. ${ }^{246}$

Given this current legal landscape in which all injured research participants have difficulty recovering under the tort system and several classes of research participants are prevented from receiving compensation altogether, continued reliance on the tort system is misguided at best and a dereliction of a moral obligation at worst.

${ }^{236}$ See Abdullahi v. Pfizer, Inc., 562 F.3d 163, 169 (2d Cir. 2009), cert. denied, 130 S. Ct. 3541 (2010).

${ }^{237}$ Id. at 170 .

${ }^{238} I d$.

${ }^{239} I d$. at $170-72$.

${ }^{240} \mathrm{Id}$.

${ }^{241} I d$.

${ }^{242}$ Ford \& Tomossy, supra note $234, \S 3.3$

${ }^{243} \mathrm{Id}$.

${ }^{244} \mathrm{Id}$.

${ }^{245} I d . \S 1$.

${ }^{246}$ Given these circumstances, courts should take efforts to ensure that plaintiffs have a genuine possibility of legal remedy in a foreign tribunal before dismissing cases on the ground of forum non conveniens. Jolyon Ford and George Tomossy argue that "it is difficult to accuse injured subjects ... of inconvenient 'forum shopping' where they seek to sue a defendant research corporation in its home jurisdiction, where that defendant might itself have been shopping around for a foreign trial site holding the least likelihood of . . legal accountability." Id. $\S 3.3$. 


\section{NON-COMPENSATION IS AN IMPEDIMENT TO U.S. RESEARCH}

In the past decade, the global research landscape has undergone a revolution. Biomedical research has become an increasingly global enterprise. ${ }^{247}$ Multinational trials are conducted in countries around the world, and are increasingly subject to many national regulatory regimes. ${ }^{248}$ In the past decade, nearly every country that sponsors, hosts, or conducts substantial amounts of research has mandated compensation for injured research participants. ${ }^{249}$ By not requiring systematic compensation, the United States has become a moral outlier and risks having important biomedical advances delayed.

\section{A. The Globalization OF BIOMEdiCAL RESEARCH}

Over the past decade, the biomedical research enterprise has become increasingly globalized, with research trials increasingly moving away from the United States and Western Europe. ${ }^{250}$ Countries outside the United States and Europe were home to only 6.2 percent of trials in 1995 , but were home to 20.9 percent in $2005 .^{251}$ The number of countries serving as trial sites outside the United States more than doubled in the ten years between 1995 and $2005 .{ }^{252}$

The number of FDA-regulated research investigators around the world has undergone a similar shift away from the United States and Europe. ${ }^{253}$ In the United States, the number of FDA-regulated research investigators has dropped an average of 5.5 percent annually since 2002 , while the number of investigators outside the United States has grown by 15 percent annually during the same period. ${ }^{254}$

Private industry trials have also undergone a migration. In 2004, Merck conducted half of its clinical trials outside the United States. ${ }^{255}$ In 2006 , Wyeth Pharmaceuticals conducted 70 percent of its trials outside the United States and Western Europe. ${ }^{256}$ In 2007, Tufts Center for the Study of Drug Development predicted that leading pharmaceutical companies will conduct up to 65 percent of their clinical trials abroad in the next few years. ${ }^{257}$ Given the increasing globalization of research and the requirement that research conducted abroad comply with the laws of the host country, U.S.-sponsored research must increasingly comply with other countries' research regulations.

\section{B. CONSENSUS to COMPENSATE AmONG COUNTRIES InVOLVED IN RESEARCH}

In the past ten years, many of the countries that sponsor, host, or conduct substantial amounts of research have implemented policies to ensure that research participants are systematically compensated in the event of research-related

${ }^{247}$ See Glickman et al., supra note 13 , at 816-17.

${ }^{248}$ Id. at $817-18$.

${ }^{249}$ Presidential COMM'N, supra note 82, at app. IV.

${ }^{250}$ Glickman et al., supra note 13 , at 816 .

${ }^{251} \mathrm{Id}$. at 818 . Western Europe was home to forty percent of trials in 1995 , and thirty-six and a half percent of trials in $2005 . I d$.

${ }^{252} I d$. at 816.

${ }^{253} \mathrm{Id}$.

${ }^{254}$ See Carolyne R. Hathaway et al., Looking Abroad: Clinical Drug Trials, 63 FooD \& DRUG L.J. 673 (2008).

255 adriana Petryna, When Experiments Travel: Clinical Trials and the Global SEARCH FOR HUMAN SUBJECTS 13 (2009).

${ }^{256}$ Id.

${ }^{257}$ Hathaway et al., supra note 254, at 674. 
injuries. ${ }^{258}$ In the past decade, thirty-one European countries have mandated compensation for research-related injuries. ${ }^{259}$ These European countries join several research-intensive countries outside of Europe-including Australia, Brazil, China, India, Israel, Japan, South Africa, and Uganda-that have all mandated compensation for research-related injuries. ${ }^{260}$ While some have merely required that free medical care and financial compensation be provided as needed, other policies are more elaborate.

In 2001, the European Parliament and the Council of the European Union issued a directive mandating that E.U. member states implement systematic compensation for research-related injuries by $2004 .{ }^{261}$ Under the directive, a clinical trial may be conducted only if "provision has been made for insurance or indemnity to cover the liability of the investigator and sponsor" as evaluated and verified by a research ethics committee. ${ }^{262}$ Because the E.U. directive does not set forth the specific contours of the requirement, E.U. member states have interpreted the requirement in a variety of ways. ${ }^{263}$

Germany had long required research sponsors to purchase insurance to cover injuries to research participants. ${ }^{264}$ Under German law, insurance must cover

${ }^{258}$ For a general discussion of the limited rights provided to research participants in the United States contrasted with rights provided in European clinical trials, see Robert Steinbrook, Compensation for Injured Research Subjects, 354 NEW ENG. J. MED. 1871 (2006) (noting that "despite decades of discussion and recommendations by national commissions, sponsors and institutions are not required to provide either free medical care or compensation . . . In contrast, many European countries mandate the provision of clinical-trials insurance, through which subjects are often covered regardless of fault.").

${ }^{259}$ See European Forum for Good Clinical Practice, The Procedure for the EThical Review of Protocols for Clinical Research Projects in Europe and Beyond: Question 31 (2010) [hereinafter EUROPEAN FORUM].

${ }^{260} \mathrm{See}$ INDIAN COUNCIL OF MED. RESEARCH, ETHICAL GuIDELINES FOR BIOMEDICAL RESEARCH on Human Participants 29 (2006) (India); Med. Research COUNCIL of S. AFr., Guidelines on ETHICS FOR MEDICAL RESEARCH: GENERAL PRINCIPLeS app. IV, $\S 1.1$ (2002) (South Africa); NAT'L Health \& Med. Research Council, National Statement on Ethical Conduct in Human RESEARCH 38 (2007) (Australia); NAT'L HEAlth COUNCIL, Resolution No. 196/96 ON RESEARCH INVOLVING HUMAN SUBJECTS (1987) [hereinafter BRAZIL COMPENSATION] (Brazil); UGANDA NAT'L COUNCIL FOR SCl. \& TECH., NATIONAL GUIDElines FOR RESEARCH INVOLVING HuMANS AS Research Participants 28 (2007) (Uganda); GoOd Clinical Practice (BoARd Order No. 3), Art. 43 (2003) (China) (cited in PRESIDENTIAL COMM'N, supra note 82, at app. IV).

261 See Council Directive 2001/20, 2001 O.J. (L 121) 34 (EC).

${ }^{262} \mathrm{Id}$. at arts. $3.2(\mathrm{f}), 6.3(\mathrm{~h})$. E.U. member states were required to transpose the directive into national laws, regulations, and procedures by May 2003 and to implement them by May 2004. Id. at art. 22(1).

${ }^{263}$ For example, countries have established various insurance minimum thresholds. Poland has adopted a graduated approach to insurance requirements. For research trials with fewer than ten participants, insurance coverage must total at least $€ 500,000$. For trials with more than 100 participants, insurance must cover at least $€ 5$ million. EUROPEAN FORUM, supra note 259, at 31-35. Spain requires insurance coverage of at least $€ 250,000$ per subject. Id. at 31-36.

The European Union is currently revisiting its approach. Because the directive granted member states flexibility in implementing requirements, it has "led to a situation where Member States have slightly divergent national provisions based on identical concepts" in ways that "make multinational clinical trials more burdensome and expensive." EUROPEAN COMM'N OF HEALTH \& CONSUMERS Directorate-General, Revision of the 'CliniCal Trials Directive' 2001/20/EC: Concept PAPER SUBMITTED FOR PUBLIC CONSULTATION 8 (2011), available at http://ec.europa.eu/ health/files/clinicaltrials/concept_paper_02-2011.pdf [hereinafter EUROPEAN COMM'N]. Under proposed revisions, sponsors of research that poses only minimal risk of harm to participants may not be obligated to provide insurance or indemnification. The revision could also result in member states indemnifying directly any damages resulting from clinical trials within their borders. Id. at 12 .

${ }^{264}$ INST. OF MED., supra note 72 , at 189. 
economic loss, but not pain and suffering. ${ }^{265}$ Injured research participants must show that the research intervention caused the participant's injury, and injuries must occur within three years of the conclusion of research, to be compensable. ${ }^{266}$ The amount of any insurance payment is capped at $€ 600,000$ per injured participant, and up to $€ 120$ million per trial. ${ }^{267}$

Under Spanish law, participants injured as a result of participating in research are entitled to no-fault compensation that covers both the physical and economic consequences of those injuries. ${ }^{268}$ The law also establishes a presumption that injuries suffered within a year of the trial were caused by the trial. ${ }^{269}$ To the extent that injuries are not otherwise covered by insurance during a clinical trial, Spanish law makes the sponsor of a trial, the principal researchers, and the medical director of the hospital in which research is carried out jointly liable. ${ }^{270}$ The sponsor must have insurance coverage of at least $€ 250,000$ per research participant. ${ }^{271}$

In the Netherlands, a sponsor may be discharged of the obligation to purchase insurance if a research ethics committee determines that participation carries no inherent risk. ${ }^{272}$ If the obligation is not waived, insurance must cover death and injury to the subject occurring during, or in the five-year period immediately following, the trial. ${ }^{273}$ Insurance need not cover injury that would have occurred had the individual not participated in research. ${ }^{274}$ Insurance must cover at least NLG1,000,000 (approximately $\$ 640,000$ ) per subject, NLG15,000,000 (less than $\$ 10$ million) per research project, and NLG20,000,000 (less than $\$ 13$ million) per insurance year for all research conducted by an institution. ${ }^{275}$ The informed consent form must disclose the extent of insurance, if any, for each research protocol. ${ }^{276}$

Outside of Europe, the countries most involved in the research enterprise have implemented their own policies to ensure that research participants receive compensation in the event of injury. ${ }^{277}$ Some countries have relatively straightforward policies, requiring simply that research ethics committees ensure that adequate arrangements to compensate injured research participants are in place before allowing research to proceed. Other countries have more elaborate policies and justifications for these policies.

Under Ugandan law, once injury occurs, an evaluation is made regarding the extent to which the injury resulted from research. ${ }^{278}$ If injuries are classified as "probably" or "definitely" related to participation in research, participants are entitled to free medical treatment for their injuries and to financial or other

\section{${ }^{265} \mathrm{Id}$. \\ ${ }^{266} \mathrm{Id}$.}

267 See, e.g., Arzneimittelgesetz [AMG] [Medicinal Products Act], Dec. 12, 2005, BundescesetzBlatt, Teil I [BGBL. I] at 3394, $\S 88$, last amended by Gesetz [G], May 25, 2011, BGBL I at 946 , art. 1 (Ger.).

${ }^{268}$ Gainotti \& Petrini, supra note 120 , at 5.

${ }^{269}$ See, e.g., INST. OF MED., supra note 72, at 189.

$270 \mathrm{Id}$.

${ }^{271}$ Gainotti \& Petrini, supra note 120 , at 6.

272 Ministry of Health, Welfare \& Sport, International Publication Series Health, Welfare and Sport, No. 2, The Medical Research InVOlving Human SubJects ACT $\$ 4.1$ (2000).

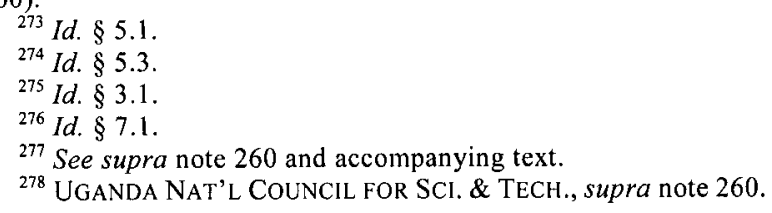


assistance as would compensate them "for any resultant impairment, disability or handicap."279

Brazil has the most expansive system in place to compensate those who are injured as a result of participating in research. ${ }^{280}$ Under the Brazilian system, compensable injuries include the "possibility of injury to the physical, psychic, moral, intellectual, social, cultural, or spiritual dimensions of the human subject."281 Under Brazilian law, the "researcher, the sponsor and the institution must assume full responsibility for providing comprehensive care to the research subjects." 282 Research participants who suffer any type of injury resulting from participation in research, regardless of whether or not it was listed in the consent document, have the right to receive comprehensive medical care, as well as compensation. ${ }^{283}$

Several countries, including the United Kingdom, South Africa, Australia, New Zealand, ${ }^{284}$ and-de facto-Singapore, ${ }^{285}$ have adopted compensation systems modeled on the Guidelines on Compensation for Trial Related Injuries promulgated by the Association of the British Pharmaceutical Industry. ${ }^{286}$ Discussed in more detail in Part V.C, these guidelines set forth parameters for compensating injured research participants that have been applied in countries around the world.

As set forth above, nearly every country that is substantially involved in the research enterprise has implemented systematic compensation for research-related injuries; every country, that is, except for the United States, the world's leading sponsor of research. ${ }^{287}$

\section{LACK OF SYSTEMATIC COMPENSATION DELAYS IMPORTANT U.S.-SPONSORED BIOMEDICAL RESEARCH}

Given the emerging consensus among many of the countries substantially involved in the research enterprise that injured research participants are entitled to free medical care and necessary financial compensation, sponsors of research that are unwilling to compensate injured research participants are at risk of having their research blocked by foreign research ethics committees. This concern is not merely hypothetical. In 2008, a major trial funded primarily by the NIH was to be rolled out at 200 international sites, 100 of which were in Europe. ${ }^{288}$ Late in the planning

${ }^{279} \mathrm{Id}$.

${ }^{280}$ See BRAZIL COMPENSATION, supra note 260. Brazil has implemented a more comprehensive view of the right to health. The Brazilian Constitution of 1988 granted the right to health to all citizens, and mandated the creation of a national healthcare system. João Biehl et al., Judicialisation of the Right to Health in Brazil, 373 LANCET 2182, 2183 (2009) ("The Brazilian Constitution of 1988 granted the right to health to all citizens and mandated the creation of a national health-care system.").

281 BRAZIL COMPENSATION, supra note $260, \S \mathrm{II} .8$.

282 Id. $\$$ V.5.

${ }^{283}$ Id. $\$$ V.6.

${ }^{284}$ U.M. Thatte et al., Review of Policies for Injuries to Research Participants in India, $35 \mathrm{~J}$. MED. ETHICS 133, 138 (2009).

285 Sing. Ministry of Health, National Medical Ethics Committee's Recommendations ON CliniCal TRIals: UPdate Focusing ON Phase I TRIALS $\$ 16$ (a) (2007), available at http://www.moh.gov.sg/content/dam/moh_web/Publications/Guidelines/National\%20Medical\%20Ethi cs\%20Committee $\% 20$ Guidelines/2007/NMEC\%20Compn\%20Clin\%20Trials_24\%20May\%2007_final public_clean.pdf.

${ }^{286}$ Id.; Thatte et al., supra note 284 , at 138.

${ }^{287}$ See Glickman et al., supra note 13, at 817-18 (showing numbers of clinical trial locations by country); supra Part III.B.

${ }^{288}$ James D. Neaton et al., Regulatory Impediments Jeopardizing the Conduct of Clinical Trials in Europe Funded by the National Institutes of Health, 7 CLINICAL TRIALS 705, 707-08 (2010). 
stages, NIH notified those involved that it would not serve as sponsor if required to compensate injured research participants. ${ }^{289}$ As a workaround, the NIH asked a grant recipient, the University of Minnesota, to assume sponsorship of the trial in what became one of the first instances of a U.S. university sponsoring an NIH-funded, multi-center, multi-national trial. ${ }^{290}$ This workaround required several months of intense, time-consuming negotiations, resulted in substantial increases in trial costs for both the NIH and the University of Minnesota, and caused disruption at the clinical sites, many of which had already selected participants who became ineligible due to the delay. ${ }^{291}$

On another occasion, a U.S. sponsor of research conducted in Mali was ordered by a monitor from the WHO to purchase clinical trial insurance, after the trial had begun, to comply with Malian law. ${ }^{292}$ In response, the sponsors contacted clinical insurance companies about providing insurance; all were reluctant to insure a trial that had already begun. It took several months to straighten out the insurance requirement, delaying valuable research. ${ }^{293}$

More recently, in the spring of 2011, the Indian government noticed that several leading pharmaceutical companies-Wyeth, Quintiles, Lilly, Amgen, Bayer, Bristol Mayer, Sanofi, PPD, and Pfizer-had not paid the compensation required under Indian law to research participants who died while participating in research. ${ }^{294}$ The Drug Controller General of India made clear that if the pharmaceutical companies did not pay the mandated compensation, they would not be allowed to conduct trials in India. ${ }^{295}$ This situation is currently unresolved.

By not mandating compensation, the United States has become a moral outlier in terms of protecting research participants, and U.S. sponsors of research risk having their research delayed or halted when conducted abroad. As discussed in Part V, the cost of mandating compensation for research-related injuries is minimal. The cost to the U.S. biomedical industry of not compensating injured research participants-and the potential delay of biomedical advances-threatens to be considerably greater.

\section{THE UNITED STATES SHOULD IMPLEMENT NO-FAULT COMPENSATION}

The United States's continued reliance on the tort system to compensate injured research participants-despite a changed legal landscape and a changed global research landscape - is misguided at best, and a dereliction of a moral obligation at worst. The tort system is a particularly problematic way of ensuring that injured research participants receive compensation. Most injured research participants are

${ }^{289} I d$. at 712 .

${ }^{290} \mathrm{Id}$.

291 Id. at 713 .

${ }^{292}$ Malaria Vaccine Dev. Branch Div. of Intramural Research, Clinical Trial Insurance for Phase 1 and 2 Vaccine Trials (Mar. 22, 2006) (presentation on file with the author). In May 2004, a collaborative research enterprise between the National Institute of Allergy and Infectious Diseases, an institute within the $\mathrm{NIH}$, and a university in Mali was set to begin trials of a potential malaria vaccine. Because insurance/self-insurance was required under the law of Mali, conducting research without an insurance/self-insurance system in place rendered the research noncompliant. $I d$.

${ }^{293}$ Id.

${ }^{294}$ Kounteya Sinha, Clinical Trials Claimed 25 Lives in 2010, Only 5 Paid Compensation, TIMES OF INDIA (June 6, 2011, 1:40 AM), http://articles.timesofindia.indiatimes.com/2011-06-06/india/ 29624892_1_clinical-trials-drug-controller-general-dcgi.

295 Id 
unable to show that a duty has been breached, many will have difficulty proving causation, all participants have a signed informed consent document that can limit or preclude recovery in assumption-of-risk jurisdictions, and many will be unable to show that their injury was the researcher's fault. Moreover, a complex and evolving patchwork of statutes and case-law leaves several classes of research participantsparticipants in federal research and international participants-unable to access the U.S. legal system.

This Part examines two proposed solutions to the inadequacies of the tort system, including modifying the language in informed consent documents and implementing a no-fault compensation system. The Part concludes that only a nofault compensation system ensures that injured research participants have adequate access to compensation. After analyzing several proposed no-fault compensation systems, this Part concludes that an insurance/self-insurance requirement similar to that implemented in countries around the world would most effectively and efficiently compensate injured research participants. This Part details parameters for implementing a no-fault compensation system, both in the United States and in countries around the world, that has potential to harmonize varying national compensation requirements and thereafter examines and addresses potential critiques of such a proposal.

\section{A. Proposed Solutions}

As described above, injured research participants face serious challenges to obtaining compensation through the tort system. This Part poses two possible solutions to this problem ranging from: (1) the very modest: merely modifying the informed consent language to make clear to participants that they retain very limited legal remedy in the event of research-related injuries; to (2) an overhaul: implementing a no-fault compensation system. ${ }^{296}$ Implementing no-fault compensation best ensures that injured research participants receive compensation for their injuries. It also requires the most political will to implement. Should that political will fail to materialize, the language in informed consent documents should be modified to reflect accurately the legal landscape for injured research participants.

\section{Modified Disclosure}

The language in informed consent documents must be modified to more accurately reflect the legal remedies available to injured research participants. Research participants who enroll in research are not aware of the extent to which they are legally unprotected in the event of a research-related injury. In fact, the language of informed consent documents mandated by federal regulation — stating that participation in research does not mean surrendering legal rights ${ }^{297}$ misleadingly suggests that injured research participants have legal rights that they

${ }^{296}$ This Article does not seriously consider modifying the tort system. Modifications to the tort system would likely be unduly burdensome to implement and would be insufficient to protect injured research participants. Modifications to the tort system would not be able to overcome the barriers posed by the requirement of fault, assumption of risk, sovereign immunity, forum non conveniens, and Kiobel v. Royal Dutch Petroleum, discussed in more detail in Part III.

${ }^{297}$ The language generally used is: "You will not be giving up any of your legal rights by signing this consent form" or "you have the right to pursue legal remedy if you believe that your injury justifies such action." 
retain. Given how few injured research participants have any chance of recovering under the tort system, the language in the informed consent document is misleading at best.

A minor revision of the language in informed consent documents could alert research participants to the fact that they retain very limited legal rights in the event of a research-related injury. Federal regulations could require, or research institutions could voluntarily include, the following language in informed consent documents:

While you are permitted to bring suit in the event of injury, existing law and policy make it hard for you to obtain money damages if you are injured (or almost impossible if you are an international participant or a participant in federal research). The cost of any injury will likely be borne by you, or by any private insurance that you have.

This proposed modification confers two main advantages. First, such disclosure permits research participants to make a truly informed decision about participating in research. For those who argue that informed consent implies an acceptance of risks associated with research that relinquishes an institution from obligations to compensate injured research participants - an argument that, as discussed above in Part III.C, is overly legalistic and insufficiently protective of research participantsinformed consent must be truly informed. Research participants are likely to believe that the tort system in the United States protects them in the event of injury. As presented in this Article, the tort system provides very limited protection. Modifying the informed consent language permits research participants to make a truly informed decision to participate in research.

Second, this language makes clear the potential consequences of research injuries to sponsors of research. Given that the extent to which injured research participants are legally unprotected has not been clear, research sponsors may be unaware that injured research participants have such limited legal remedy. Requiring research institutions to acknowledge the reality faced by injured research participants could prompt some institutions to modify their policies and offer compensation and care to injured research participants.

This proposal has potential negative consequences. Research participants who consider participating in research might reconsider upon learning the extent to which they are unprotected in the event of a research-related injury. If fewer people choose to participate in research, researchers may have increased difficulty recruiting research participants, which may slow the development of important medical advances. But the risk of losing potential research participants as they learn the truth is inherent in the disclosure of any risks during the informed consent process, and this has never justified withholding important information.

\section{Mandated No-Fault Compensation System}

A more comprehensive proposal to address the inadequacies of the tort system is to implement no-fault compensation. No-fault compensation has certain advantages over the tort system. The tort system is a time-consuming process, and its adversarial nature can discourage viable and important claims. ${ }^{298}$ The tort system is also expensive, with high transactions costs. ${ }^{299}$ Participants injured for reasons other than

${ }^{298}$ See, e.g., Gainotti \& Petrini, supra note 120 , at 2.

${ }^{299} \mathrm{Id}$. 
fault fall outside the tort system entirely. ${ }^{300}$ Even among those participants whose injury is fault-based, the tort system can be unpredictable; the tort system has a tendency to under-compensate or fail to compensate most injured participants, while over-compensating others. ${ }^{301}$

No-fault compensation systems, by contrast, generally allow for speedier resolution of claims, are generally less costly to administer, and permit a larger percentage of payment to go to the injured party. ${ }^{302}$ Because the determination of fault becomes irrelevant, no-fault compensation systems tend to encourage open communication among the parties, which allows sponsors and researchers to assess the circumstances that gave rise to injury and provide feedback to make future research safer ${ }^{303}$ Although limited empirical data exist about no-fault compensation systems for research-related injuries, what data there are suggest that no-fault systems in this area are cost-effective. ${ }^{304}$

No-fault compensation systems for research-related injuries are demonstrably feasible, as nearly every country that sponsors, hosts, or conducts substantial amounts of research has implemented them. ${ }^{305}$ No-fault compensation can take a variety of forms, and the umbrella term "no-fault compensation" is broad enough to encompass systems as diverse as workers' compensation, personal auto insurance, and the vaccine court established to compensate those injured by vaccination, as discussed in more detail below.

No-fault compensation systems do have detractors, however, and no-fault compensation has been criticized for lacking tort law's deterrent effect, ${ }^{306}$ for its cost, ${ }^{307}$ and for its potential to short-change victims. ${ }^{308}$ But properly implemented,

${ }^{300}$ See Scott, supra note 137 , at 423 ; Resnik, supra note 89 , at 283-85.

${ }^{301}$ See McEwin, supra note 123, at 737; O'Connell, supra note 123 , at 63 ("The attempt to achieve a fair and rational method for the compensation of victims has been displaced by a form of litigation lottery.").

${ }^{302}$ See, e.g., INST. OF MED., supra note 72, at 190-91; Mark M. Hager, No-Fault Drives Again: A Contemporary Primer, 52 U. MIAMI L. REV. 793, 807 (1998) (noting that no-fault pays a higher proportion of premium income to claimants than does the tort system, reduces over- and undercompensation, and delivers compensation more quickly than does the tort system); Mariner, supra note 95, at 121; McEwin, supra note 123, at 739 ("Many studies have demonstrated that the tort system is not only slower to provide compensation than no-fault but also tends to overcompensate small losses and undercompensate large losses.").

${ }^{303}$ See, e.g., Resnik, supra note 89, at 283.

${ }^{304}$ See infra Part V.D for more information on the cost-effectiveness of no-fault compensation systems for research-related injuries.

${ }^{305}$ See supra Part IV.B.

${ }^{306}$ See, e.g., Hager, supra note 302, at 794-95 ("No-fault's disadvantages are chiefly two-fold: (1) loss of tort law's purported role in deterring unsafe driving; and (2) loss of tort law's purported corrective justice function in securing recompense for injury victims from culprits who inflict injury."); Henry Huang \& Farzad Soleimani, What Happened to No-Fault? The Role of Error Reporting in Healthcare Reform, 10 Hous. J. HEALTH L. \& POL'Y 1, 7-8 (2009) ("Critics also argue that no-fault systems produce the wrong incentives for doctors and victims. Simply put, without fault in the compensation process, there is no (or at least less) stigma associated with fault, and therefore less incentive to prevent mistakes.").

${ }_{307}$ See, e.g., Hager, supra note 302, at 808 ("Existing no-fault has not brought reduced premiums, despite claims by advocates that it should."); Huang \& Soleimani, supra note 306, at 7 ("Despite these harsh criticisms of tort, the no-fault alternative has ample detractors. One of its biggest sticking points is cost.").

${ }^{308}$ See, e.g., Gary T. Schwartz, Auto No-Fault and First-Party Insurance: Advantages and Problems, 73 S. CAL. L. REV. 611, 651 (2000) ("[N]o-fault's denial of pain and suffering compensation to the victims of negligent driving is a denial that raises a fairness problem with no-fault."); Lindsay J. Stamm, The Current Medical Malpractice Crisis: The Need for Reform to Ensure a Tomorrow for Oregon's Obstetricians, 84 OR. L. REV. 283, 306 (2005) ("Critics of no-fault, 
i.e., with insurance premiums determined by a research institution's safety record, no-fault compensation can retain some level of deterrence while remaining costeffective. And the criticism that some would receive more under the tort system is counterbalanced by the ability of no-fault compensation to make more equitable and rational payments. ${ }^{309}$

Ultimately, a no-fault compensation system goes furthest in ensuring that research participants-those who accept additional risk to help generate important benefits for society-are compensated in the event of injury. Only no-fault compensation systems are broad enough to ensure coverage for the participants killed or seriously injured in the FIAU research discussed in the Introduction: research that had serious consequences but for which researchers were cleared of negligence or carelessness.

\section{B. No-FAulT COMPENSATION SYSTEMS}

Although perhaps requiring significant political will to put into practice, implementing a no-fault compensation system is also the most effective way to ensure that injured research participants receive compensation for their injuries. ${ }^{310}$ This Part examines the various no-fault compensation systems that have been proposed-a no-fault insurance/self-insurance requirement, a specialty court like the vaccine court, a pooled or funded compensation system, and mandating personal coverage - and evaluates their merits.

A number of criteria have been set forth for evaluating a no-fault compensation system. Though not putting forth concrete proposals, the 1982 President's Commission set forth the following characteristics of an ideal compensation system: treat like cases alike, make fair payment for the harm sought to be remedied, and disburse payments with maximum efficiency and minimum administrative cost. ${ }^{311}$ An ideal system should also incentivize research sponsors to manage and mitigate risks to participants and should require minimal new bureaucracy. Moreover, any U.S. no-fault compensation system must comply with current legal limitations in the spending of federal funds. Both the Anti-Deficiency Act $^{312}$ and the Adequacy of Appropriations $\mathrm{Act}^{313}$ prevent agencies that receive federal funds from incurring future financial obligations that have not already been fully funded by a

notably plaintiff's attorneys, argue it would shortchange victims who could fare better under the existing tort system.").

${ }^{309}$ See, e.g., Hager, supra note 302 , at 806 (noting that studies have "found existing nofault schemes superior to tort for rational and efficient delivery of compensation").

${ }^{310}$ For this reason, a number of scholars have advocated no-fault compensation in the area of research-related injuries. See, e.g., Michael Traynor \& Erin Wallace, Clinical Trials: Emerging Issues Regarding Globalization of Pharmaceutical Research, Insurance, Informed Consent, Securities Litigation, and Public Policy, Presentation at CLE Seminar on Emerging Issues in Biotechnology Law (Sept. 6-7, 2007), available at http://www.cooley.com/files/tbl_s5SiteRepository/FileUpload21/1348/ Article $\% 20-\% 20$ Sep $\% 2007 \% 20-\% 20$ Traynor\%20-\%20Clinical\%20Trials.pdf ("[University of Washington's no-fault compensation system] bears serious consideration in the U.S. as evolving ethical standards here as well as legal requirements in foreign countries call for it to be implemented. Although the empirical data is lacking, this approach might hold the promise of reducing the incidence of substantial tort liability claims and attendant increased liability insurance costs.").

${ }^{311}$ See, e.g., PRESIDENT'S COMM'N, supra note 43, at 127.

${ }^{312}$ See Limitations on Expending and Obligating Amounts, 31 U.S.C. $\S 1341$ (a)(1)(A) (2010) (forbidding the obligation of funds not already appropriated).

${ }^{313}$ See No contracts or purchases unless authorized or under adequate appropriation, 41 U.S.C. $\$ 11$ (a) (2010) (forbidding the government to obligate itself by contract "unless the same is authorized by law or is under an appropriation adequate to its fulfillment"). 
congressional appropriation. ${ }^{314}$ These laws have formed the basis of the current NIH policy of not compensating injured research participants. ${ }^{315}$ Finally, an ideal no-fault compensation system would take steps towards harmonizing the various national compensation policies.

As set forth above, nearly every country that sponsors, hosts, or conducts substantial amounts of research has mandated a no-fault insurance/self-insurance requirement. This Part concludes that an insurance/self-insurance requirement best satisfies the goals of compensating all injured research participants fairly, quickly, with the least administrative burden, and in accordance with federal regulations. It also has the advantage of potentially satisfying legal requirements worldwide.

\section{Insurance/Self-Insurance Requirement}

The first proposed no-fault compensation system, an insurance/self-insurance requirement, is the most common system of compensating injured research participants around the world. ${ }^{316}$ These compensation systems operate much like workers' compensation systems. ${ }^{317}$ Under an insurance/self-insurance requirement, research sponsors are required to buy insurance, or must agree to compensate injured research participants directly, before research is allowed to proceed. ${ }^{318}$ Compensation generally covers the medical and financial costs of injury; recovering for unlimited pain and suffering, punitive damages, and negligence are generally not permitted. ${ }^{319}$ Compensation is generally received in exchange for an agreement not to sue. ${ }^{320}$

A no-fault insurance/self-insurance requirement for research injuries satisfies many of the criteria set forth above: like injured research participants are treated alike, injured research participants receive fair payment for their harm, and payments can be made with maximum efficiency and minimum administrative burden. ${ }^{321}$ The requirement that sponsors purchase insurance or agree to compensate injured research participants directly incentivizes sponsors of research to reduce risk, the cost of insurance may be tied to the institution's safety record and to the thoroughness and safety of the research protocol, and the more careful and thorough the researchers are, the cheaper the insurance should be. ${ }^{322}$ Self-insurance places the

${ }^{314}$ See 31 U.S.C. $\$ 1341(a)(1)(A) ; 41$ U.S.C. $\S 11$ (a).

${ }^{315}$ See, e.g., Charles Marwick, Compensation for Injured Research Subjects, 297 JAMA 1854, 1854 (1998) (justifying the NIH's policy of non-compensation because it is unable "to provide funding for health care costs that go beyond the contract period"); What Else Should I Know About Clinical Research?, Nat'L INST. OF Child Health \& Human Dev. (Feb. 9, 2011), http:/www.nichd.nih.gov/health/clinicalresearch/aboutclinicalresearch.cfm (citing the AntiDeficiency Act and the Adequacy of Appropriations Act research as the reason why "participants in a federally funded study can not [sic] sue the federal government for a claim of injury, loss, or damage").

${ }^{316}$ See, e.g., PRESIDENTIAL COMM'N, supra note 82, at app. IV.

${ }^{317}$ Though subject to the criticism discussed below, workers' compensation systems have also been heralded as an "enormous boon to efficiency" that addresses the goals of efficiency, deterrence, corrective justice, and distributive justice, and "coincided with an enormous reduction in industrial accident rates." Jeffrey O'Connell \& John Linehan, Neo No-Fault Early Offers: A Workable Compromise Between First and Third-Party Insurance, 41 GONZ. L. REV. 103, 133-34 (2005).

${ }^{318}$ See, e.g., Council Directive 2001/20, 2001 O.J. (L 121) 34 (EC), art. 3.2(f).

${ }^{319}$ THE LEWIN GRP., supra note 129 , at 19.

${ }^{320} \mathrm{Cf}$. id. ("In exchange for the certainty of reasonably speedy compensation on a no-fault basis, injured employees are required to give up their rights to sue their employers.").

${ }^{321}$ See, e.g., O'Connell \& Linehan, supra note 317 , at 133-34.

${ }^{322} \mathrm{Cf}$. id. at 134 (noting that under workers' compensation, "producers retain an incentive to provide a safe workplace environment" as "reflected in the employer's experience-rated premiums"). 
full costs of any injury squarely on the institution, incentivizing the institution to manage and mitigate risk. And depending on how it is implemented, an insurance/self-insurance requirement may require only minimal new bureaucracy.

Workers' compensation systems have been criticized for inadequately compensating those injured in ways that might apply to systems for compensating injured research participants. These criticisms must be acknowledged and dealt with in any proposed system for compensating those injured by research. In delineating what constitutes a compensable event, architects of any compensation system must be mindful of the shortfalls in workers' compensation systems. And while workers' compensation systems generally provide no recourse to the tort system, no-fault compensation systems for research injuries could provide limited recourse to the tort system, permitting injured research participants to choose between payments that are quick and certain but more limited, and payments that are larger but less certain and more time-consuming to obtain. ${ }^{323}$

Depending on how it is structured, an insurance/self-insurance requirement could comply with the statutory mandates of the Anti-Deficiency Act or the Adequacy of Appropriations Act. ${ }^{324}$ An insurance policy involves a fixed payment at the outset of research and shifts any unfunded liability to the insurer rather than the research sponsor. Private sponsors of research and entities receiving federal funds can purchase insurance out of their research budget without bumping into the limitations of the Anti-Deficiency Act or the Adequacy of Appropriations Act. The same may not be true for federal agencies which, under regulatory policy, are not generally able to purchase private insurance without a statutory grant of authority. ${ }^{325}$

Most importantly, an insurance/self-insurance requirement complies with international compensation systems, as this is precisely the system adopted by many other countries. ${ }^{326}$

\section{Specialty Court}

A second no-fault compensation system that scholars and commissions have suggested is a no-fault specialty court modeled on the vaccine court. ${ }^{327}$ The vaccine court is often hailed as a model system for compensating injured research participants because it is a health-related court that has successfully implemented no-fault compensation. ${ }^{328}$ The mission of the vaccine court is to provide a "swift, flexible, and less adversarial alternative to the often costly and lengthy civil arena of traditional tort litigation." 329

${ }^{323}$ Id. (noting that those injured exchange "the guarantee of prompt, but limited, pay-outs" for the "indeterminate opportunity for tort's riches").

${ }^{324}$ See, e.g., SECRETARY'S TASK FORCE, supra note 77, at V-4 ("[I]f institutions chose to fund such a system with insurance, the premiums ascribable to the insurance could be paid from grant or contract funds under current department policies.").

3251 Office of the General Counsel, U.S. Gen. Accounting Office, Principles of FEDERAL APPROPRIATIONS LAW 4-176 (3d ed. 2004), available at http://www.gao.gov/special.pubs/ d04261 sp.pdf.

${ }^{326}$ Presidential CoMM'N, supra note 82, at Appendix IV.

327 See, e.g., Marwick, supra note 315 , at 1854 ("One possible avenue for funding any compensation for adverse events in clinical trials would be to set up a mechanism similar to the Vaccine Injury Compensation Act.").

${ }^{328}$ See, e.g., THE LEWIN GRP., supra note 129 , at 1 (" $[\mathrm{T}]$ o this day the only national standard for no fault procedures and federal compensation guidelines is the National Childhood Vaccine Injury Act ....").

329 Vaccine Program/Office of Special Masters, U.S. COURT OF FED. ClaIMS, http://www.uscfc.uscourts.gov/vaccine-programoffice-special-masters (last visited Nov. 17, 2011) 
Those injured as a result of receiving certain compulsory childhood vaccines may use the vaccine court to petition the federal government for monetary damages. ${ }^{330}$ To win an award, a claimant must present medical records that show that a child developed one of several listed adverse events soon after vaccination. ${ }^{331}$ Compensation covers medical and legal expenses, loss of future earning capacity, and up to $\$ 250,000$ for pain and suffering. A death benefit of up to $\$ 250,000$ is also available. ${ }^{332}$ The compensation program is funded by a seventy-five cent surtax on the purchase of each vaccine, ${ }^{333}$ thereby adopting and implementing a system of riskspreading by which those actually vaccinated pay into a fund that compensates the few who are injured by vaccination. ${ }^{334}$

A vaccine court-like compensation system satisfies several of the criteria set forth above: like participants are treated alike, injured research participants receive fair payment for the harm suffered, and the payments are disbursed more efficiently than they are under the tort system. The vaccine court model does not satisfy several of the remaining criteria. The vaccine court model pools the risk of all injuries, making payments to those injured from a collective pot of money. While pooled risk may be appropriate for vaccines-identifying which manufacturer produced the vaccine that gave rise to injury could be unduly burdensome-such risk sharing is not necessary for research and eliminates incentives for sponsors to manage or mitigate risk. ${ }^{335}$

An additional disadvantage is that the vaccine court model requires an entirely new bureaucracy, and it is not clear that the political will necessary to create a specialty court for compensating research-related injuries exists. The vaccine court was established in a moment of political crisis during which many feared that large tort awards would force all vaccine manufacturers out of the market. ${ }^{336}$ The political circumstances surrounding compensation for research-related injury are not similarly dire. For nearly four decades, national advisory committees have called for a system

[hereinafter Vaccine Program]; Statement on National Vaccine Injury Compensation Program: Before the House Committee on Criminal Justice, Drug Policy, and Human Resources, 106th Cong. (1999) (statement of Thomas E. Balbier, Jr., Director, Nat'l Vaccine Injury Comp. Program, U.S. Dep't of Health \& Human Servs.), available at http://www.hhs.gov/asl/ testify/t990928b.html ("42 percent of petitions adjudicated under the Program have been awarded compensation. This compares to a compensation rate of only 23 percent for those who file medical malpractice lawsuits through the usual tort system. On average, it takes only two years to resolve claims and issue any appropriate payments.").

${ }^{330}$ See, e.g., Vaccine Program, supra note 329.

331 The Office of Special Masters, U.S. Court of Fed. Claims, Guidelines for Practice Under The NATIONAL VACCINE INJURy COMPENSATION Program 8 (2004), available at http://www.uscfc.uscourts.gov/sites/default/files/OSM.Guidelines.pdf.

${ }^{332} \mathrm{Id}$. at 4.

${ }^{333}$ See, e.g., Gainotti \& Petrini, supra note 120 , at 3.

${ }^{334}$ Critiques of the vaccine court system generally relate to the fact that rates of compensation have not been adjusted since implementation, and that the system is still more adversarial than anticipated. See, e.g., Rob Henson, Inoculated Against Recovery: A Comparative Analysis of Vaccine Injury Compensation in the United States and Great Britain, 15 TULSA J. COMP. \& INT'L L. 61, 89-92 (2007).

${ }^{335}$ Gainotti \& Petrini, supra note 120 , at 3.

${ }^{336}$ See, e.g., Scott, supra note 137 , at 422 . At the time, large jury awards had forced several vaccine manufacturers to consider the potential costs of lawsuits; many concluded that they could no longer afford to stay in business. Most vaccine manufacturers ceased production, and the last remaining major manufacturer threatened to do so. The vaccine court was thus seen as a timely solution to an imperiled supply of vaccines. Id.; Gainotti \& Petrini, supra note 120, at 3. 
to compensate those injured by research ${ }^{337}$ During that time, scandals emerged revealing ethically impermissible or unreasonably risky research. ${ }^{338}$ None of this has resulted in public clamoring for systemic reform. Given the lack of demonstrated political will, the political system is unlikely to lead to the implementation of a vaccine court-like system to compensate injured research participants.

Whether a vaccine court model could comply with the Anti-Deficiency Act and the Adequacy of Appropriations Act is unclear. ${ }^{339}$ The vaccine-court-implementing statute imposes a fee on the sale of each vaccine, an identifiable transaction that shifts the costs of the system back to the consumer of the vaccine. ${ }^{340}$ Unlike the vaccine system, the research enterprise does not include an easily identifiable transaction on which this fee may be levied. A flat-rate, per-participant fee could comply with the Anti-Deficiency Act and the Adequacy of Appropriations Act because the cost of compensation would be knowable at the outset of research. But, other means of collecting fees may not comply. Whether such a system could satisfy the international requirements that sponsors of research agree to insure or indemnify against research-related injury is also unclear.

\section{Compensation Fund}

A third no-fault compensation model that has been proposed is a compensation fund similar to that of the Radiation Exposure Compensation Act (RECA), the September 11 th Victim Compensation Fund (the "9/11 Compensation Fund"), and the BP Oil Spill Compensation Fund. These funds disburse money pooled from a collective pot to a defined group of injured individuals. This is an approach that has already been implemented as a way of compensating injured research participants.

Between 1945 and 1962, the U.S. government conducted nearly 200 atmospheric nuclear weapons tests across swaths of the Southwest. ${ }^{341}$ Years later, many who were injured as a result of exposure to radiation filed class-action lawsuits that were dismissed by the appellate courts. ${ }^{342}$ Congress decided to provide relief to those who were injured, and on October 5, 1990, passed the RECA. ${ }^{343}$ The Act implemented a flat-rate compensation model for those who contracted certain diseases following exposure to radiation. ${ }^{344}$ To receive compensation, claimants had to show that they resided in an area with significant fallout from the nuclear testing and that they had contracted a listed medical condition. ${ }^{345}$ Claimants were not

337 See, e.g., ADVISORY COMM. ON HUMAN RADIATION EXPERIMENTS, supra note 46; PRESIDENT'S COMM'N, supra note 43; SECRETARY's TASK FORCE, supra note 77.

${ }^{338}$ See, e.g., EMANUEL ET AL., supra note 9; Levine, supra note 1; Reverby, supra note 10; Stephens, supra note 6 .

${ }_{339}$ Compare Anti-Deficiency Act, 31 U.S.C. $\S 1341(a)(1)(A)(2006)$, and Adequacy of Appropriations Act, 41 U.S.C. $\S 11$ (a) (2006), with National Injury Compensation Program, 42 U.S.C. $\S \S 300 \mathrm{aa}-1$ to -34 (2006).

${ }^{340}$ Stephen D. Sugarman, Cases in Vaccine Court - Legal Battles over Vaccines and Autism, 357 NEW ENG. J. MED. 1275 (2007), available at http://www.nejm.org/doi/full/ 10.1056/NEJMp078168.

${ }_{341}$ See Radiation Exposure Compensation Act (RECA), U.S. DEP'T OF JUSTICE, http://www.justice.gov/civil/torts/const/reca/about.htm (last updated Aug. 6, 2011) [hereinafter $R E C A]$.

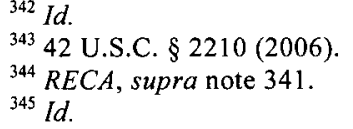


required to establish causation. Individuals who lived downwind of the test site and subsequently became ill received flat-rate compensation of $\$ 50,000 .^{346}$

A compensation fund has been implemented more recently in the aftermath of 9/11. ${ }^{347}$ In the 9/11 Compensation Fund, a large amount of money was appropriated by the federal government out of which those injured could make a claim for money damages. Kenneth Feinberg, appointed Special Master of the 9/11 Compensation Fund, administered the fund and made determinations about how money would be paid out. ${ }^{348}$ Calculations were made based on future earning potential, presumed pain and suffering, minus any collateral source of income. ${ }^{349}$ An accepted offer could not be appealed. ${ }^{350}$ Families unhappy with the offer were able to appeal in a nonadversarial, informal hearing to present their case however they wanted. ${ }^{351}$ A similar approach has been adopted to compensate those injured as a result of the BP oil spill. $^{352}$

Compensation funds offer many advantages and satisfy many of the criteria for an ideal no-fault compensation system. All injured research participants are treated alike, and money is distributed with maximum efficiency and minimum administrative burden. One downside is that funded compensation systems do require a new centralized bureaucracy. It is also unclear whether compensation funds comply with the Anti-Deficiency Act and the Adequacy of Appropriations Act. For the same reasons as the vaccine court proposal, it is unclear whether a compensation fund could satisfy international requirements that sponsors of research agree to insure or indemnify against research-related injury.

Feinberg argued that future compensation funds "should provide the same amount of compensation for all eligible claimants" 353 because different amounts "promoted inefficiency and delay." ${ }^{354}$ Flat-rate compensation does not satisfy several important requirements, most notably that injured research participants be made whole for the injuries they suffer. For some research participants, compensation of $\$ 50,000$-adjusted upward for inflation-is far more than is needed; for others, it is far from adequate. A flat-rate compensation system may be needed when compensating a large group, the cost and cause of whose injuries cannot be accurately measured; it is not necessary for research-related injuries-injuries incurred by known and well-monitored participants. Last, a flat-rate compensation system creates odd incentives for research sponsors to manage and mitigate risk; researchers have strong financial incentives not to injure anyone, but once a research participant is injured, researchers have no financial incentive to minimize any resulting injury.

${ }^{346} \mathrm{Id}$.

${ }^{347}$ September 11 th Victim Compensation Fund of 2001, 67 Fed. Reg. 11,233, 11,236 (Mar. 13, 2002) (codified at 28 C.F.R.pt. 104).

${ }^{348} \mathrm{Id}$.

${ }^{349}$ Id. $\$ \$ 104.41-.47$.

${ }^{350}$ Id. $\$ 104.31(\mathrm{~b})(\mathrm{l})$.

Id. $\$ 104.33$.

352 About the Fund, BP Claims Fund AssistancE (July 21, 2010), http://www.thebpclaimsfund.com/. (2006).

${ }^{353}$ Kenneth R. Feinberg, The September IIth Victim Compensation Fund, 32 LITIGATION 14, 17

$$
{ }^{354} I d .
$$




\section{Personal Insurance}

A final model for compensating injured research participants is a variant of the system that is already in place: compensation through an individual's personal health insurance. In this variation, injured research participants would file claims with their own insurers. The individual's own insurance then pays the claim-generally for medical care, perhaps for financial injuries if mandated statutorily-on a no-fault basis.

A personal insurance compensation model satisfies some of the criteria set forth above: such a system is efficient, requires no new bureaucracy, and by shifting the burden of injury back to participants, does not conflict with the Anti-Deficiency Act and the Adequacy of Appropriations Act.

A personal insurance compensation model fails in several key ways. First, and perhaps most fundamentally, like injured research participants are not treated alike. The level of compensation depends on the particular insurance that an injured research participant has. Under this system, uninsured research participants will not receive any compensation. ${ }^{355}$ Second, the system provides no economic incentives for research institutions to manage and mitigate the risks of research. Last, this system clearly does not satisfy the international requirement that sponsors of research agree to insure or indemnify against research-related injury. These key failures render this proposal insufficient to address the current inadequacies of the tort system for compensating injured research participants.

All proposed modifications offer some improvement over the current system in terms of ensuring that injured research participants receive compensation. Although it arguably has the most to recommend it independently, the insurance/self-insurance requirement has a critical additional advantage over other proposals: it brings our laws into accord with those in the rest of the world, and readies U.S.-sponsored multinational research for cross-border approval.

\section{Proposed Parameters}

This Article endorses a no-fault compensation system using an insurance/selfinsurance requirement. In addition to satisfying many of the criteria set forth above, an insurance/self-insurance requirement could bring U.S. law into accord with the laws of the rest of the world. An insurance/self-insurance requirement also appropriately retains an element of risk deterrence.

The proposal set forth below borrows procedurally from various no-fault compensation systems around the world, but modifies and adapts these policies to work best with systems already in place for reporting research-related injuries. The substantive provisions of the proposal are meant to provide a framework that can be implemented in countries around the world, permitting flexibility and intra-country differences when they do not disproportionately burden multinational research.

The Association of the British Pharmaceutical Industry promulgated guidelines on compensation for research injuries ${ }^{356}$ that have been modified and adopted by a number of diverse countries-including the United Kingdom, South Africa,

\footnotetext{
${ }^{355}$ The Patient Protection and Affordable Care Act may alter the number of uninsured people living in the United States. MOSES \& SINGER LLP, supra note 141.

356 The Ass'N OF THE BRitish Pharm. Indus., CliniCal TRIAl Compensation Guidelines $\S 1.2$ (Jan. 1, 1994), available at http://www.abpi.org.uk/our-work/library/guidelines/Pages/ctcompensation.aspx.
} 
Australia, New Zealand, ${ }^{357}$ and, de facto, Singapore. ${ }^{358}$ These guidelines illustrate both that compatible systems can be implemented in a number of diverse countries, and that guidelines can be promulgated and accepted by private industry-i.e., those who have traditionally been most resistant to compensation mandates.

\section{Process}

This proposal requires that sponsors of research compensate injured research participants. As a necessary precondition to getting research approved by a research ethics committee, research sponsors would be required to check a box certifying that they had made arrangements to compensate injured research participants. Research sponsors could choose whether to compensate through third-party insurance, or whether to self-insure and compensate injured research participants directly. ${ }^{359}$ To the extent research sponsors under-insure, they will be required to compensate injured research participants directly.

A modified version of the adverse event reporting system triggers the compensation mechanism. Today, most countries require that investigators report adverse events arising from research to authorities. ${ }^{360}$ These reports detail the type of injury and whether, in the investigator's opinion, the injury was likely attributable to the research intervention. Under this proposal, the filing of an adverse event report for research injuries would trigger institutional compensation mechanisms.

As under the current adverse event reporting system, the investigator would make an initial determination as to the likelihood of the injury being related to research. The investigator is generally qualified to make an initial determination because he or she often has the most detailed knowledge about the research intervention and often has the most specialized knowledge about any underlying conditions being studied. The investigator may be self-interested in finding injuries unrelated to the research, which counsels against relying exclusively on the investigator's assessment. Though investigators would be expected to deal fairly in making their assessment, the initial assessments would be subject to review and injured research participants would be entitled to the procedural safeguards of notice and opportunity to be heard.

An injury found by the investigator to be related to the research triggers the institution's compensation mechanism. The injured research participant would then be given a time frame within which to provide documentation of unreimbursed medical costs and financial harms arising from the injury. The institution should make a settlement offer that covers these documented losses. If an injured research participant accepts payment under the compensation program, the payment fully

${ }^{357}$ Thatte et al., supra note 284 , at 133.

${ }^{358}$ Sing. Ministry OF HEALTH, supra $285, \S 16$ (a) ("Most of the centres themselves or the sponsors of the trial follow the guidelines of the Association of British Pharmaceutical Industry (ABPI) on compensation for adverse events resulting from participation in a clinical trial.").

${ }^{359}$ Karen Moe, Director and Assistant Vice Provost For Research, Univ. of Wash., Presentation to the President's Commission for the Study of Bioethical Issues (Nov. 17, 2011), available at $\mathrm{http} / / /$ bioethics.gov/cms/meeting-seven (noting that the University of Washington performed this analysis and concluded that self-insurance was the more cost-effective option).

${ }^{360}$ For a discussion of various adverse event reporting systems, see WORLD ALLIANCE FOR

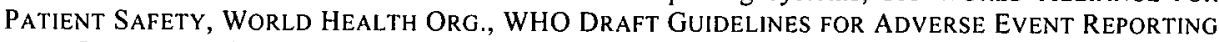
AND LEARNING SYSTEMS (2005); INT'L CONFERENCE ON HARMONISATION OF TECHNICAL Requirements for Registration of Pharm. for human Use, Maintenance of the iCH Guideline on Clinical Safety Data Management: Data Elements for Transmission of INDIVIDUAL CASE SAFETY REPORTS E2B(R2) (Feb. 5, 2001). 
extinguishes further legal claims. If the injured research participant does not accept the offer, the participant may proceed to court. ${ }^{361}$ For the reasons set forth in Part III, many tort law claims arising from research injuries are unlikely to succeed. Because of the limitations of the tort system, the protections of the compensation system must be sufficiently robust.

To the extent an investigator concludes that the injury did not arise from research, the injured research participant must receive notification of the initial assessment and be provided an opportunity to present documentary or in-person evidence stating otherwise. Each institution must designate a committee that can review the claim and any additional evidence presented. This task can be delegated either to the IRB (already presented with adverse event reports), the Data Safety Monitoring Board (already tasked with monitoring safety), or a standing committee within the entity. The committee will review the evidence presented and make an offer upon finding that the injury arose from research.

The institutional evaluation procedure must be set forth in clear language in the informed consent form. Institutions may also choose to appoint a representative to assist injured research participants in presenting their claims for compensation. Claims that cannot be settled through this process may proceed to litigation or to arbitration by an independent body, as required by local law. ${ }^{362}$

Claims must be brought within a period of time after the injury, and within a period of time following the conclusion of research. This de facto statute of limitations means that some late-filing injured research participants will be denied access to no-fault compensation. This concern is particularly serious for research participants with injuries that emerge much later. To the extent the research sponsor is still available to make this determination at the time the injury is discovered and can make a determination with minimal additional burden, the research participant shall be entitled to review in accordance with the institution's no-fault compensation system. The injured research participant would still have the option to bring suit, subject to the limitations discussed in Part III.

\section{Research Covered}

Other countries and other proposals have carved out two types of research as being exempt from insurance/self-insurance requirements: minimal risk research ${ }^{363}$ and therapeutic research. ${ }^{364}$ For the reasons set forth below, this proposal would not carve out these types of research.

${ }^{361}$ O'Connell \& Linehan, supra note 317 , at 134.

${ }^{362}$ See, e.g., Ass'N OF THE BRITISH PhaRm. Indus., supra note $356, \S 4.3$ ("In any case where the company concedes that a payment should be made to a patient but there exists a difference of opinion between company and patient as to the appropriate level of compensation, it is recommended that the company agrees to seek at its own cost ... the opinion of a mutually acceptable independent expert, and that his opinion should be given substantial weight by the company ....").

${ }^{363}$ See, e.g., Netherlands Decree of 23 June 2003 containing rules for compulsory insurance in medical research involving human subjects, art. 4(1), available at http://www.ccmo.nl/download/verzekeringsbesluit 2003-eng.pdf ("If the committee responsible for assessing the trial protocol in question believes the clinical trial represents no risk to the subjects, at the sponsor's request it may, upon its approval of the protocol, exempt the sponsor from the obligation to take out insurance."); EUROPEAN COMM'N, supra note 263, $\S 2.4 .2$ (considering "[r]emoving insurance/indemnisation requirements for low-risk trials: This policy option would remove the insurance requirement for clinical trials which typically pose a low risk for trial subjects").

${ }^{364}$ See, e.g., PRESIDENT'S COMM'N, supra note 43, at 132-35. 
The first class of research that has been carved out from insurance/selfinsurance requirements is minimal risk research. The primary argument for exempting minimal risk research is that requiring sponsors to purchase insurance or self-insure is thought to be onerous in relation to the low probability that anyone will actually suffer injury. ${ }^{365}$ Some research is classified as minimal risk because it carries only a remote chance of causing serious injury. But this low probability does not ensure that no one will become injured, and does not eliminate the moral imperative to compensate those who do become injured by research. If the remote possibility of injuries occurs, those injured by research should not be left uncompensated. Accordingly, even sponsors of minimal risk research must agree to purchase insurance or agree to compensate injured research participants directly. The expectation is that sponsors of most minimal risk research-particularly sociological, survey, or other non-interventional studies-will choose to self-insure rather than purchase insurance, thereby fulfilling the moral obligation at no cost.

The second class of research that has been exempted from compensation requirements, or subject to lowered compensation requirements, is therapeutic research. ${ }^{366}$ The rationale behind exempting therapeutic research is two-fold. First, because participants enroll in research in the hopes of obtaining a benefit, they are acting in a self-interested manner, or so may not have the same ethical claim for compensation if injury befalls them. But the mere prospect of a benefit does not undermine the fact that research participants are taking on additional risk in a way that benefits society.

Second, some have suggested that injured research subjects should not be compensated if they were injured as a result of participating in therapeutic research because it could be difficult to determine whether the injury was caused by the research or by the participant's underlying disease. ${ }^{367}$ In at least some therapeutic research trials, such as the FIAU trial discussed in the Introduction, the injury can be pretty easily attributed to the research. It would, in fact, be strange if the injured or killed FIAU participants could not receive compensation for their injuries simply because they enrolled in therapeutic research, when the injury they suffered bore no relation to the underlying disease, and was far in excess of what they could have expected from their disease. Although there may be cases in which determining whether the injury was caused by the research or by the underlying disease is more difficult, this determination is a question of fact and can be evaluated much like other questions of fact.

Compensation should be provided to all injured research participants, regardless of whether the research was therapeutic or not, provided that the injury exceeds that which would reasonably occur due to any underlying illness or treatment associated with the disease. ${ }^{368}$

${ }^{365}$ The European Union is currently reconsidering its decision not to exempt minimal risk research. EUROPEAN COMM'N, supra note $263, \S 2.4 .2$.

${ }^{366}$ See, e.g., Gainotti \& Petrini, supra note 120 , at 4 (noting that France has different standards for therapeutic and nontherapeutic research).

${ }^{367}$ See, e.g., PRESIDENT'S COMM'N, supra note 43, at 132-35.

${ }^{368}$ This approach is consistent with the opinions of the 1977 Task Force. See, e.g., SECRETARY'S TASK FORCE, supra note 77 , at VI-9 (concluding that participants in both therapeutic and nontherapeutic research should be entitled to no-fault compensation, provided that injury is defined narrowly). 


\section{Compensable Injuries}

Defining when a research injury is compensable is undeniably more complex than defining a compensable workers' compensation claim, ${ }^{369}$ or even defining a compensable vaccine injury. ${ }^{370}$ Although defining a compensable research-related injury is difficult, it is not impossible.

Defining a compensable event involves a two-pronged determination: first, whether the injury is of a type that is entitled to compensation; and second, whether the circumstances under which the injury occurred merit compensation. As to the first determination, only injuries that result in documentable financial harms are entitled to compensation. ${ }^{371}$ Minor injuries, such as bleeding or bruising, should be dealt with on-site and on-the-spot. In the context of therapeutic research, compensation is due when a measurable injury occurs that is in excess of what would have occurred had the underlying disease been treated with the standard of care.

The second determination pertains to the circumstances in which injuries should be compensated. The simple answer is that injuries should be compensated that on balance of the probabilities, arise from research. ${ }^{372}$ Compensation may be due even when injuries arise from aspects of the research other than the particular medicinal product being tested. ${ }^{373} \mathrm{Abdullahi}$ participants who were in fact injured as a result of receiving a deliberately low dose of the comparator drug should be entitled to nofault compensation even though their injury did not arise from the intervention being tested, because they were injured in excess of what likely would have occurred had they received the standard of care. ${ }^{374}$ Compensation may also be due for injuries arising from procedures necessary for research but not treatment. Compensation may be reduced by comparative negligence to the extent the participants' own negligence contributed to the injury. ${ }^{375}$

\section{Types of Compensation}

Injured research participants are entitled to compensation for the otherwise uncompensated costs associated with death and serious physical and mental injury. In accordance with many of the compensation systems in place in other countries,

${ }^{369}$ The only question presented in the workers' compensation system "is whether or not the injury 'arose out of and in the course of employment' ...." O'Connell \& Linehan, supra note 317, at 132 (internal citations omitted).

${ }^{370}$ PRESIDENTIAL COMM'N, supra note 82, at 69.

${ }^{371}$ Using serious adverse event reporting as a trigger appropriately confines the compensation mechanism to non-trivial injuries. See, e.g., ASs'N OF THE BRITISH PHARM. INDUS., supra note 356, $\S 1.4$ ("Compensation should only be paid for the more serious injury of an enduring and disabling character... and not for temporary pain or discomfort or less serious or curable complaints."); PRESIDENT'S COMM'N, supra note 43, at 129 (limiting benefits to "nontrivial bodily injuries or death as a result of their participation in covered research"). Research-related injuries that are not serious, e.g., bleeding or bruising from a blood draw, should be treated on-site. These injuries would not generally otherwise be compensable in court. See, e.g., PRESIDENT's COMM'N, supra note 43, at 81 ("For subjects with minor, short-lived injuries (who constitute a large proportion of injured subjects), the provision of free, on-the-spot medical care dispenses with any need for formal 'compensation' for research injuries.").

${ }^{372}$ See, e.g., AsS'N OF THE BRITISH PHARM. INDUS., supra note 356, § 1.2.

${ }^{373}$ See, e.g., id. $\$ 3.2$.

${ }^{374}$ See supra Part III.

${ }^{375}$ See, e.g., PRESIDENT's COMM'N, supra note 43, at 129 ("Benefits should be reduced or eliminated when injury results from the failure of the subject reasonably to conform to the provisions of the research.") (emphasis added). 
the United States could-but needs not-consider compensating documented and demonstrable lost wages and loss of future earnings. As is the case in vaccine courts and the 9/11 Compensation Fund, a death benefit should be paid to the estate of participants who die as a result of participating in research. Institutions should have discretion to compensate for pain and suffering, but should not be required to do so. ${ }^{376}$ Compensation received through collateral sources of payment-including life insurance proceeds, pensions, and workers' compensation payments-satisfy the requirement that participants be made whole. ${ }^{377}$

Some countries have implemented payment caps limiting payments per participant and per clinical trial. ${ }^{378}$ If payments due are high enough to hit payment caps, payments to individuals are reduced proportionally. ${ }^{379}$ These caps deny compensation to injured research participants. It is entirely possible that payment caps would permit those injured and killed by the FIAU research to recover only a small proportion of the actual costs of their injury, unfairly shifting the financial burden back to the injured research participants. This proposal does not recommend implementing a payment cap.

Some countries have implemented monetary thresholds that must be met before claims for compensation can be brought. ${ }^{380}$ These thresholds are implemented to limit the number of claims, thereby reducing the cost of compensation systems. These thresholds also deny some injured research participants the possibility of being made whole. Before any monetary threshold can be put in place, empirical data about the types and number of claims that would be foreclosed should be obtained. This proposal suggests that compensation be provided without regard to thresholds, but that the possibility of instituting a threshold should be reevaluated in three to five years.

\section{Cross-Border Applicability}

Each country should be allowed to determine the amounts that must be paid to the country's own injured research participants. Research conducted abroad must comply with the compensation limits set forth by the host country. For countries that do not require compensation, it is strongly urged that sponsors agree to compensate

${ }^{376}$ These parameters are in line with compensation systems of other nations and with the compensation provided by other U.S. no-fault compensation systems. See, e.g., The Danish Liability for Damages Act, pt. I (2007) (Den.), available at http://www.patientforsikringen.dk/en/Love-ogRegler/Lov-om-klage-og-erstatningsadgang/Behandlingsskader.aspx (compensating for personal injury, loss of earnings, pain and suffering, permanent injury, and loss of earning capacity, among other areas); Injury Prevention, Rehabilitation, and Compensation Act 2001 (amended 2007), pt. 2, $\S 26(1)$ (N.Z.) (compensating for the death of a person, physical injuries suffered by a person, and mental injury); BRAZIL COMPENSATION, supra note 260, at art. II.8 (compensating injuries to the "physical, psychic, moral, intellectual, social, cultural, or spiritual dimensions of the human subject").

${ }^{377}$ This is how the 9/11 Compensation Fund was implemented. Feinberg, supra note 353, at 15 .

${ }^{378}$ See, e.g., Danish Act on the Right to Complain and Receive Compensation within the Health Service (2009), pt. 4, $\$ 50$ (Den.), available at http://www.patientforsikringen.dk/en/Love-ogRegler/Lov-om-klage-og-erstatningsadgang/Lægemiddelskader.aspx (capping damages to individual injured research participants at DKK5 million per injured person, approximately one million U.S. dollars); Medical Research (Human Subjects) Compulsory Insurance Decree, Stb. 2003, p. 66, art. 3(1) (Neth.).

(capping insurance payments at $€ 450,000$ per subject and $€ 3,500,000$ per clinical trial).

${ }^{379}$ See, e.g., Medical Research (Human Subjects) Compulsory Insurance Decree, supra note 378 , at 66 , art: $3(1)$.

${ }^{380}$ See, e.g., Danish Act on the Right to Complain and Receive Compensation within the Health Service, supra note 378 , at pt. $4, \S 46$ (permitting claims that exceed DKK3000, approximately five hundred U.S. dollars). 
injured research participants at the levels required by the nearest neighboring country that requires compensation, or at levels mandated by countries with comparable per capita income levels.

While it is hoped that countries would begin to harmonize the amount and types of compensation required, harmonization is not necessary. Because sponsors must carry sufficient insurance or agree to self-insure to cover any costs not covered by insurance, sponsors could make independent assessments based on the countries in which they will conduct trials about the amount of insurance necessary.

Procedures must be set forth that ensure that injured international research participants can contest any adjudication of their claim. Each country would be permitted to decide the form this resolution should take. In countries that require that injured research participants not waive their legal rights, injured research participants should be allowed to bring suit in court, and sponsors of research should consent to be sued; other countries could appoint an independent body as an official arbitrator. If sponsors of research agree to comply with the compensation requirements of host countries, the current battle over complying with many national regimes could be eliminated.

\section{Implementation}

Implementing this proposal in the United States would require either modifications to the federal regulations governing research or voluntary participation. If voluntary compliance is not forthcoming, U.S. regulations would be modified to require that sponsors of research agree to purchase insurance or selfinsure to compensate injured research participants in accordance with local law. ${ }^{381}$ Second, the adverse event reporting already in place in the United States must be modified to require that any reported event triggers the evaluation of claims in the manner set forth above. Third, the regulations should be modified to require that research institutions set forth an internal process for reviewing decisions about the relatedness of injury to research.

While these regulatory modifications are sufficient for both privately conducted research and federally funded research conducted by grant recipients, the situation is more complex with regards to federally conducted research. The Adequacy of Appropriations and Anti-Deficiency Acts have been interpreted to limit the federal government's ability to compensate injured research participants directly; potential liabilities could exceed amounts congressionally appropriated. ${ }^{382}$ Except in limited circumstances, government appropriations law and policies generally limit the federal government's ability to purchase insurance in the absence of a statutory grant of authority. ${ }^{383}$ Government agencies may therefore need a statutory grant of authority to purchase private insurance to compensate injured research participants, and may need to look to statutory workarounds if the institutions under-insure. ${ }^{384}$

${ }^{381}$ Those institutions with sufficient funds will be permitted to indemnify injured research participants. See, e.g., Suz Redfearn, Clinical Trial Insurance (Aug. 14, 2007), available at http://www.clinpage.com/article/clinical_trial_insurance/ ("[M]ost big pharmaceutical companies don't buy clinical trial insurance. Some may instead have a dedicated risk management division on the premises. Or they know that their cash reserves are enough to handle any settlements that need to be made.").

${ }^{382}$ See, e.g., Jamie Summers, Legal and Practical Barriers to a No-Fault Compensation Program for Research Related Injuries (unpublished manuscript) (on file with the author).

${ }^{383}$ OFFICE OF THE GENERAL COUNSEL, supra note 325 , at 4-164.

${ }^{384}$ There are exceptions to this general policy that, if applicable, would allow government agencies to purchase private insurance without a statutory grant of authority. See id. at 4-180. 


\section{RESPONSE TO POSSIBLE CRITIQUES}

A number of critiques of implementing a system of compensation for research injuries suggest that no system should be implemented at all. ${ }^{385}$ These critiques include arguments that implementing a no-fault compensation system would be too costly, that the data is insufficient to show that compensation is needed, and that now is not the time to implement a no-fault compensation system given the extent to which our health insurance system is in flux. ${ }^{386}$ For the reasons set forth below, these critiques are insufficient to overcome the ethical imperative to compensate injured research participants.

\section{Costs}

The primary critique of implementing no-fault compensation for research injuries is its presumed cost. ${ }^{387}$ Many worry that the costs of implementing no-fault compensation would divert funds away from important research. ${ }^{388}$ Though there is only limited data on the scope and cost of research-related injuries, ${ }^{389}$ what data there are suggest that compensating injured research participants should not be financially burdensome.

Data from a 1976 survey conducted by the NIH, the most comprehensive data on research injuries in the United States, suggest that research-related injuries occur only infrequently. The 1976 survey data suggest that only 3.7 percent of all research participants sustained any injury. Of these, 79.2 percent had trivial injuries, while only 3.7 percent were permanently disabled, and only 0.9 percent died. ${ }^{390}$ More recent data from European countries similarly indicate a low frequency of researchrelated injuries. ${ }^{391}$ Data from the European Union suggest that the financial cost of

${ }^{385}$ See, e.g., Resnik, supra note 89 , at 284-85.

${ }^{386} \mathrm{Id}$. See also text in Parts V.D.1-D.3.

${ }^{387}$ See, e.g., Resnik, supra note 89, at 284 ("A major reason no-fault systems are not popular in the United States is that institutions and sponsors do not want to bear the burden of financing these plans.").

${ }^{388}$ See, e.g., id.

${ }^{389}$ See, e.g., INST. OF MED., supra note 72, at 191 ("The main impediment to the implementation of a compensation program for research-related injuries in the United States is that, despite decades of discussion and studies by a number of federal commissions, there remains little quantitative information regarding the number and severity of potentially compensable injuries and about the costs of implementing compensation programs.").

${ }^{390}$ See, e.g., Scott, supra note 137 , at 420.

${ }^{391}$ In an unidentified member state with approximately 200-1000 clinical trial applications per year, only fourteen claims for compensation were granted over a period of nine years. In Finland, out of almost 300,000 trial participants, the Finnish Patient Insurance Centre and the Finnish Pharmaceutical Insurance Pool received only nineteen requests for compensation between 2005 and 2010; only four led to compensation. Denmark received only twenty-seven claims for compensation over a period of ten years. See EUROPEAN COMM'N, supra note 263, at 23. It is important to note that data from Europe create an imperfect comparison; many European countries have national healthcare, under which medical bills are generally covered. Additionally, some of the plans, including the German plan, do not provide compensation for pain and suffering. Nevertheless, given that the lack of empirical data has been used to prevent implementation of compensation systems in the United States, it is also important to use the empirical data available. 
compensating research-related injuries is quite low, ${ }^{392}$ and that the costs of insurance per patient per annum are also quite low. ${ }^{393}$

More importantly, agreeing to compensate injured research participants does not itself create new costs; rather it shifts the burden of those costs from the injured research participant to the research sponsor.

\section{Not Actually a Problem?}

Others have argued that given the relative infrequency of research-related injuries, perhaps the problem is insufficiently serious to warrant any solution. ${ }^{394}$ As set forth above, there is only limited data on the scope and frequency of researchrelated injury, and what data exist are somewhat lacking. We are altogether unsure of the extent to which injured research participants bear the financial consequences of research injuries. Some might argue that if even one injured research participant is forced to bear the financial consequences of the research injury, that itself is a wrong that should be righted. ${ }^{395}$

But a practical response is more straightforward. Under this proposal, sponsors of research can choose to self-insure rather than purchasing commercial insurance. If the problem of research injuries is much smaller than anticipated or feared, the cost of compensating those who become injured will be quite low.

\section{Now Is Not the Time}

The third argument against implementing a no-fault compensation system is that the healthcare insurance system is currently in flux, and that it would be better to wait and assess the impact of current health reform efforts before layering an additional system on top of our current one. But our health system has been undergoing systemic change for much of the forty years that the possibility of compensating injured research participants has been discussed. ${ }^{396}$ Waiting until the system is settled may take years, and possibly decades. Current reform efforts, moreover, are aimed at ensuring that more Americans are covered by health

${ }^{392}$ Denmark, at the high end of the scale, paid $€ 550,000$ over a period of ten years to injured research participants, or $€ 55,000$ per year. Relative to Denmark's annual research budget of $€ 385$ million per year, the cost of compensating injured research participants is 0.01 percent of the health research budget. See Danish ReSEARCH AGEnCy, FIGURES FOR RESEARCH 2005 (Jan. 2006), available at http://en.fi.dk/publications/2006/figures-for-research-statistics-2005/figures-for-researchstatistics-2005.pdf (showing the research expenditures of Denmark to be DKK2.846 billion).

${ }^{393}$ The cost of insurance per patient per annum in Europe ranges from a low of $€ 14.50$ in Belgium, to a high of $€ 75$ in France and Germany. See EUROPEAN COMM'N, supra note 263, at 23. Relative to the other costs of conducting a biomedical research trial, these costs are negligible-even for very large trials. Some data suggest that the costs of purchasing insurance may be less than the costs of compensating research-related injuries directly. In an unidentified member state, the total amount of compensation paid out in fourteen claims over nine years was $€ 43,000$. The administrative cost for the insurers was approximately $€ 38,000$, and the total cost for the policy was approximately $€ 235,000$. Id.

${ }^{394}$ PRESIDENT'S COMM'N, supra note 43, at 65-80; NAT'L BIOETHICS ADVISORY COMM'N,, supra note 81 , at $123-25$.

${ }^{395}$ PRESIDENT'S COMM'N, supra note 43, at 80 ("Although the evidence consistently suggests that the incidence of serious injury is small, nonetheless, it is clear that at least some subjects sustain injuries as a result of their participation in federally funded or regulated research. For them, ... the question of compensation is real and of immediate importance.").

${ }^{396}$ Janet L. Dolgin \& Katherine R. Dieterich, Social and Legal Debate About the Affordable Care Act, 80 UMKC L. Rev. 45, 48-49 (2011). 
insurance. ${ }^{397}$ As Americans increasingly receive health insurance coverage, research participants should also be increasingly covered, which will presumably result in fewer instances in which injured research participants alone bear the financial costs of research injuries.

\section{CONCLUSION}

Over the past half-century, biomedical research has become increasingly regulated, with the goal of increasing participant protection. One area in which protections for research participants have fallen critically short is caring for research participants who become injured as a result of participating in research.

Over the past four decades, U.S. advisory committees have repeatedly concluded that injured research participants are entitled to compensation for any injuries suffered as a result of their participation in research. These committees have noted the inadequacy of the tort system and recommended implementation of nofault compensation. But they have offered no concrete proposals and have taken no steps to implement systematic compensation. Accordingly, the United States has continued to rely on the tort system to provide compensation for research-related injuries.

Changes in the legal landscape and the global research landscape make continued reliance on the tort system morally indefensible and an impediment to U.S. research conducted abroad. Recent decisions highlight the inadequacy of the tort system; the tort system poses challenges unique to research participants that are difficult to overcome and insurmountable for certain classes of research participants, resulting in substantial unfairness. In the past decade, the research enterprise has become increasingly global, and many of the countries that sponsor, host, or conduct substantial amounts of research have required that injured research participants receive systematic compensation. By not requiring compensation, the United States has become a moral outlier and risks having its international research embargoed, delaying potential medical advances.

This Article recommends implementing no-fault compensation for participants injured as a result of participating in research. Having reviewed a number of no-fault compensation systems, this Article proposes an insurance/self-insurance requirement that builds on research reporting systems already in place. This proposal can be implemented in the United States and in countries around the world to help harmonize various national compensation systems. This proposal satisfies the moral obligation owed to injured research participants and more equitably and effectively makes those injured by research whole.

${ }^{397} \mathrm{Id}$. at 52 ("The [Patient Protection and Affordable Care] Act promises to extend health care coverage to millions of people. Health care coverage will be made available to many not now insured."). 
Copyright of American Journal of Law \& Medicine is the property of American Society of Law, Medicine \& Ethics and its content may not be copied or emailed to multiple sites or posted to a listserv without the copyright holder's express written permission. However, users may print, download, or email articles for individual use. 